\title{
Review \\ Sex Differences in Anxiety and Depression: What Can (and Cannot) Preclinical Studies Tell Us?
}

\author{
Franco Rafael Mir 1,2,*(D) and María Angélica Rivarola 1,3 (D) \\ 1 Cátedra de Fisiología Animal, Facultad de Ciencias Exactas, Físicas y Naturales, Universidad Nacional de \\ Córdoba, Av. Velez Sarsfield 299, Córdoba X5000JJC, Argentina; arivarola@unc.edu.ar \\ 2 Cátedra de Fisiología Animal, Departamento de Ciencias Exactas, Físicas y Naturales, Universidad Nacional \\ de La Rioja, Av. Luis M. de la Fuente S/N, Ciudad Universitaria de la Ciencia y de la Técnica, \\ La Rioja F5300, Argentina \\ 3 Instituto de Investigaciones en Ciencias de la Salud (INICSA), Consejo Nacional de Investigaciones Científicas \\ y Tecnológicas, Universidad Nacional de Córdoba, Enrique Barros Esq. Enfermera Gordillo, Ciudad \\ Universitaria, Córdoba X5016, Argentina \\ * Correspondence: francomir@unc.edu.ar
}

Citation: Mir, F.R.; Rivarola, M.A. Sex Differences in Anxiety and

Depression: What Can (and Cannot) Preclinical Studies Tell Us? Sexes 2022, 3, 141-163. https:// doi.org/10.3390/sexes3010012

Academic Editor: George E. Barreto

Received: 23 December 2021

Accepted: 11 February 2022

Published: 22 February 2022

Publisher's Note: MDPI stays neutral with regard to jurisdictional claims in published maps and institutional affiliations.

Copyright: (C) 2022 by the authors. Licensee MDPI, Basel, Switzerland. This article is an open access article distributed under the terms and conditions of the Creative Commons Attribution (CC BY) license (https:// creativecommons.org/licenses/by/ $4.0 /)$.

\begin{abstract}
In recent years, the gender perspective in scientific research and sex differences in biological studies on emotional disorders have become increasingly important. However, sex bias in basic research on anxiety and depression is still far from being covered. This review addresses the study of sex differences in the field of anxiety and depression using animal models that consider this issue so far. What can preclinical studies tell us and what are their main limitations? First, we describe the behavioral tests most frequently used in preclinical research to assess depressive-like and anxiety-like behaviors in rodents. Then, we analyze the main findings, strengths, and weaknesses of rodent models of anxiety and depression, dividing them into three main categories: sex chromosome complement-biased sex differences; gonadal hormone-biased sex differences; environmental-biased sex differences. Regardless of the animal model used, none can reproduce all the characteristics of such complex and multifactorial pathologies as anxiety and depressive disorders; however, each animal model contributes to elucidating the bases that underlie these disorders. The importance is highlighted of considering sex differences in the responses that emerge from each model.
\end{abstract}

Keywords: sex chromosomes; sex hormones; mood disorders; animal models; anxiety-like behavior; depressive-like behavior

\section{Introduction}

Anxiety and depressive disorders are the most prevalent psychiatric disorders among the human population and usually present together (comorbidity). It is estimated that over 300 million people worldwide suffer from one or both of these mood disorders, and their prevalence and severity have been consistently reported as being two times more frequent in women than in men [1-3]. Despite efforts to elucidate the biological basis of these disorders, evidence remains sparse and elusive. Animal models to study the underlying mechanisms are powerful tools (with their own limitations) to better understand the etiology of anxiety and depression. It is necessary to consider ethical and methodological aspects when using experimental animals and the scope that such research will have, analyzing the advantages and limitations of preclinical studies. Moreover, even if an evolutionary psychology perspective is considered, the great differences in cognition and emotion between humans and other animals force us to be very cautious when extrapolating preclinical results to human mental health. However, a rigorous and conscientious analysis of the results obtained in animal models can help us to better understand the biological bases of human brain functioning in physiological and pathological conditions.

One major reason for the failure to identify the underpinnings of these mood disorders seems to be that, despite the clear sex differences, clinical and preclinical studies have 
historically underestimated the "sex variable", extrapolating results from male-driven experiments to both sexes. This led to discrepancies, inconsistent results, and ineffective pharmacological treatments, which encouraged the scientific community to incorporate the sex of individuals, tissues, and cells in preclinical studies [4,5].

Brain sexual differentiation is a multifactorial process that involves at least three important factors: genes, hormones, and environment. These factors interact to produce, deepen, or even erase sex differences in the biochemistry, morphology, and physiology of the nervous system [6]. Moreover, sex differences in the brain are thought to be responsible for differences between men and women in the incidence and clinical manifestations of many mental disorders $[7,8]$.

In this review, we discuss the most important evidence of sex differences in anxiety and depression found through animal models of these diseases. We also analyze the possible underlying biological mechanisms (through the lens of the unified model of brain sexual differentiation) that may account for differences between males and females in the establishment, progression, and response to pharmacological treatment. As this is a non-systematic review, we are very aware of its limitations that include our own bias in determining which studies to cite, how they are analyzed, and the conclusions drawn. There is also a possibility of drawing incorrect conclusions when a large set of studies is involved. However, we have made our best attempt to include the most salient studies following some inclusion/exclusion criteria: studies must be published in the past twenty years (a time when the first animal models to study sex chromosome complement influences on brain sexual differentiation were developed), studies must have been performed in rodents (mice or rats), studies must have measured anxiety and depressive traits in both sexes, and must have included behavioral testing along with any other biomarkers for these diseases. A better understanding of the principal factors that mediate sex differences in anxiety and depression will allow us to produce new and more effective treatments for these mental illnesses in men and women.

\section{Animal Models of Anxiety and Depressive Disorders}

The family of anxiety disorders is characterized by long-lasting, mild-to-severe feelings of anxiety and fear, while the family of depressive disorders is defined by episodicto-chronic, mild-to-severe incapacity to cope with daily life due to sadness, tiredness, difficulties concentrating, changes in weight, sleep and appetite, loss of enjoyment and pleasure and, in its most extreme form, can lead to suicide [3,9]. A good preclinical model is that which most reliably meets predictive, face, and construct validity criteria. Of course, none of the animal models developed so far meet all the validity criteria and probably will never do so due to the heterogeneous and complex symptomatology of human mood disorders. Moreover, animal model validation criteria must be constantly revised to understand more clearly the underlying biological mechanisms of mental illnesses [10-12].

Different hypotheses regarding etiological mechanisms of anxiety and depression have been proposed, including genetic and epigenetic factors, neurochemical factors (neurotransmitter alterations, i.e., monoamine, glutamate, or neuropeptides systems, dysregulation of the brain-gut microbiota axis), and psycho-environmental factors (hypothalamic-pituitaryadrenal (HPA) axis dysregulation and stress response activation). However, none of them can fully explain the underlying pathophysiological mechanisms of these mood disorders. As with other psychiatric disorders, its etiology is multifactorial and arises from the interplay of biological, psychosocial, and environmental factors. An extensive analysis of the etiology of anxiety and depression is beyond the scope of this review. Here, we will focus on sex differences in clinical and preclinical studies that have been consistently reported in the last years [13].

As a stressful situation has been implicated in triggering anxiety and depressive episodes [14,15], it is not surprising that stress exposure leads to anxiety-like and depressivelike behaviors in rodents. Rodents have a complex social structure and form tight bonds with their conspecifics, altering social organization (i.e., isolation, pup-mother separation, 
repeated cage mate changes) is a stressful experience that can induce anxiety-like and depressive-like states. The classic animal models of anxiety and depression have different chronic stress paradigms, developed as a function of achieving construct validity. The intensity, the time duration of exposure, and the kind of stressor used varies across studies.

Early maternal separation: involves subjecting pups to between 3 and $6 \mathrm{~h}$ of maternal separation during the first postnatal weeks. This produces significant levels of stress in the offspring, generating long-lasting consequences. Although it is important to consider factors such as the frequency of separation, timing, duration, and the controls used, it is considered a valid model of depression and presents sexually dimorphic differences [16].

Chronic unpredictable stress: involves repeatedly exposing animals to different mild stressors in an unpredictable sequence over several weeks. As a result, the animals show behavioral and neuroendocrine changes consistent with depression [17].

Social isolation stress: consists of isolating animals in individual cages for 4 weeks, usually during adolescence, which strongly induces the onset of features related with emotional and affective disorders, such as depression and anxiety [18].

Chronic social defeat: consists of exposing an animal to an aggressive and dominant conspecific, which generally attacks and defeats it. After repeated bouts of social defeats, the subordinated rodent shows depressive-like symptoms. One of the major disadvantages of this model is that it cannot be used in female subjects since their aggressiveness is lower and there are no confrontations [19].

Learned helplessness: is based on inescapable, uncontrollable acute exposure to an aversive stimulus (usually foot shocks). The animal learns that there is no escape, has no control over the situation, and, therefore, develops depressive-like helpless behavior. When they are re-exposed to the same aversive situation but with an easy exit, they show high escape latency rates or do not attempt to escape at all [20].

Other animal models frequently used in the study of emotional disorders such as anxiety and depression are based on surgical or chemical manipulations.

Olfactory bulbectomy: in rodents, the olfactory system forms part of the limbic system, which includes the amygdala and hippocampus. Bilateral surgical removal of olfactory bulbs triggers a set of behavioral, neuroendocrine, and physiological changes similar to those of human depression [21].

Neuroinflammation model: the relationship between depression and inflammation has been well established [22]. Although animal models based on immunogenic activation have received criticism, a lipopolysaccharide (LPS) injection, which is a potent activator of the immune system, results in anxiety and depression-related behavior. Similarly, the injection of a BCG vaccine generates a chronic inflammatory response that induces a depressive-like phenotype in rodents [23].

Hormonal models: Dysregulation of the hypothalamic-pituitary-adrenal (HPA) axis has been demonstrated in both clinical and animal studies of depression. Animal models based on the "glucocorticoid" hypothesis consist of chronic administration of exogenous corticosterone over different periods of time (weeks to months) either by oral administration through drinking water or food, subcutaneous injection, pellet implantation, or osmotic pump infusion. Anxiety- and depressive-like behaviors have been consistently reported after exogenous glucocorticoid exposure [24].

Genetic and epigenetic models: Both anxiety and depression are affective diseases that include environmental and genetic variables in their physio-pathogenesis. Therefore, in recent decades, genetic models have emerged to study these disorders. On the one hand, numerous animal lines have been developed by selective breeding in both rats and mice (for extensive review see [25]). In addition, using genetic modification techniques, numerous transgenic models and knockout $(\mathrm{KO})$ mice have been generated to study anxiety and depression. Focused on the "monoamine" hypothesis of depression, genetic modifications of serotonergic and noradrenergic systems have been generated. On the other hand, following the "neurotrophin" and the "HPA-dysfunction" hypothesis, many genetic models have also been developed enabling the investigation of candidate genes 
that possibly contribute to the disease (for review, see $[21,26,27])$. More recently, optogenetic manipulations have also been shown to effectively induce depressive-like behavior. In general, these approaches induce specific changes that mimic dysfunction of a specific brain circuit associated with depression-detailed discussion of these models is beyond the scope of this review, for an extensive review, see [28-30]. The main rodent models used in the study of anxiety and depression are summarized in Figure 1.
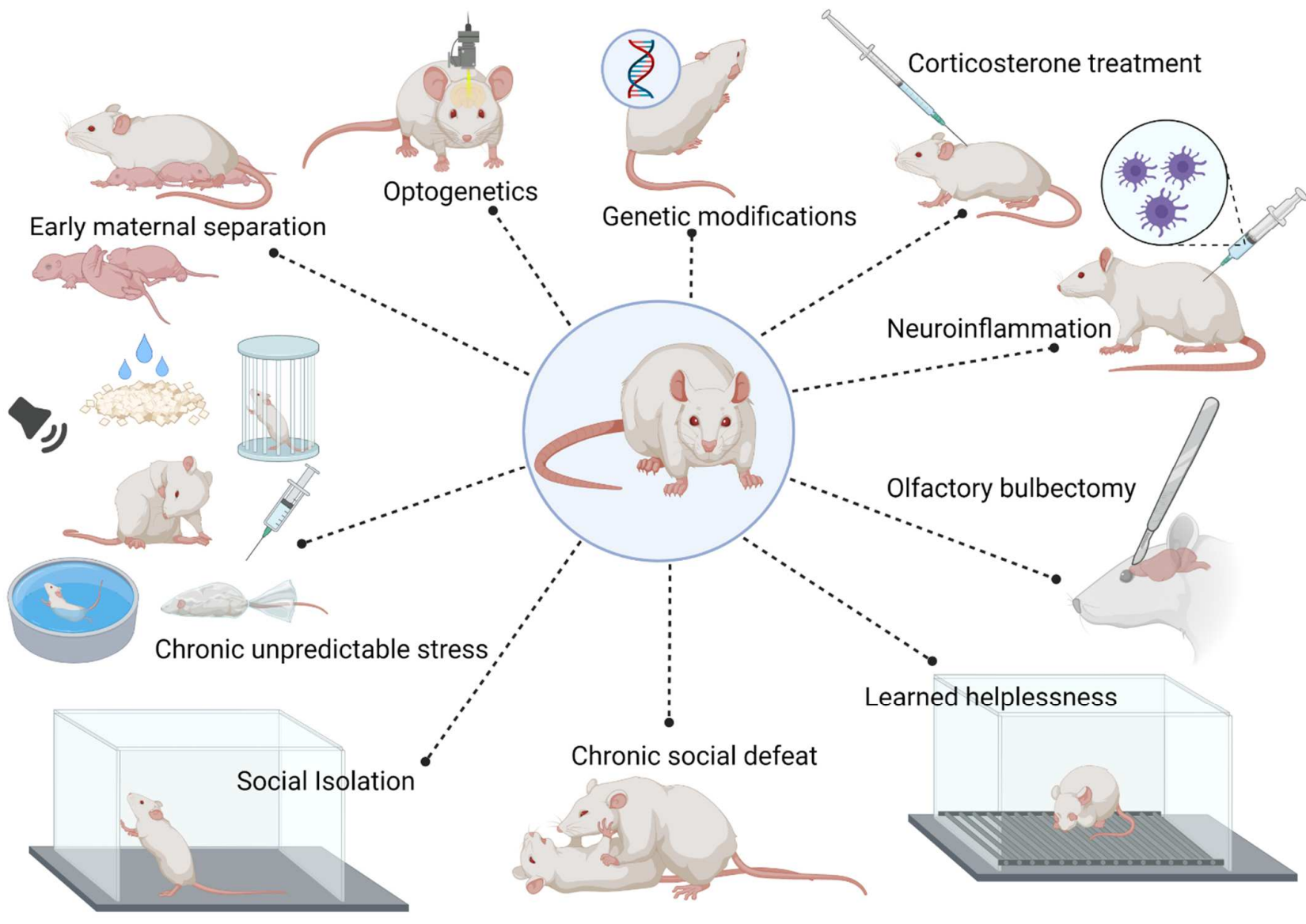

Figure 1. Animal models of anxiety and depression disorders. Most animal models are based on stress exposition at different temporal windows. However, other models have emerged by surgical, genetic, immune, and hormonal manipulations. For reference, see the main text. Created with BioRender.com (accessed on 20 December 2021).

\section{Outcomes of Anxiety-like and Depressive-like Behavior Tests}

The symptoms of anxiety and depressive disorders are very difficult to reproduce or resemble in animals due to their subjective and complex nature. However, anxiety-like and depressive-like behaviors may be successfully assessed by exploiting the innate characteristics of the broad repertoire of rodent behaviors. Several behavioral tests have been developed to analyze anxious and depressive states in rodents. Here, we present and briefly describe a comprehensive, but not complete, list of the most used and well-established behavioral tests that have reported sex differences in anxiety-like and depressive-like behavior in rodents (Figure 2). 


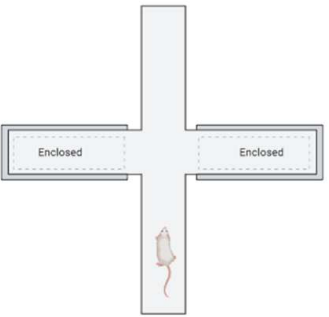

Elevated plus maze

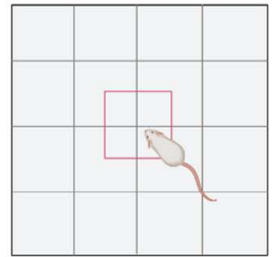

Open field test

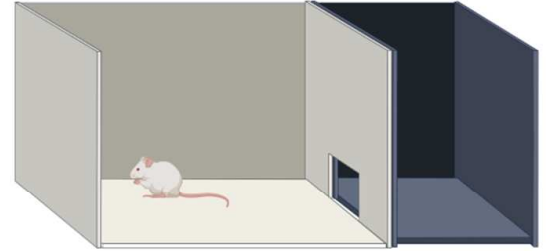

Light-dark box test

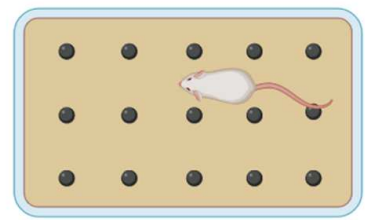

Marble burying test

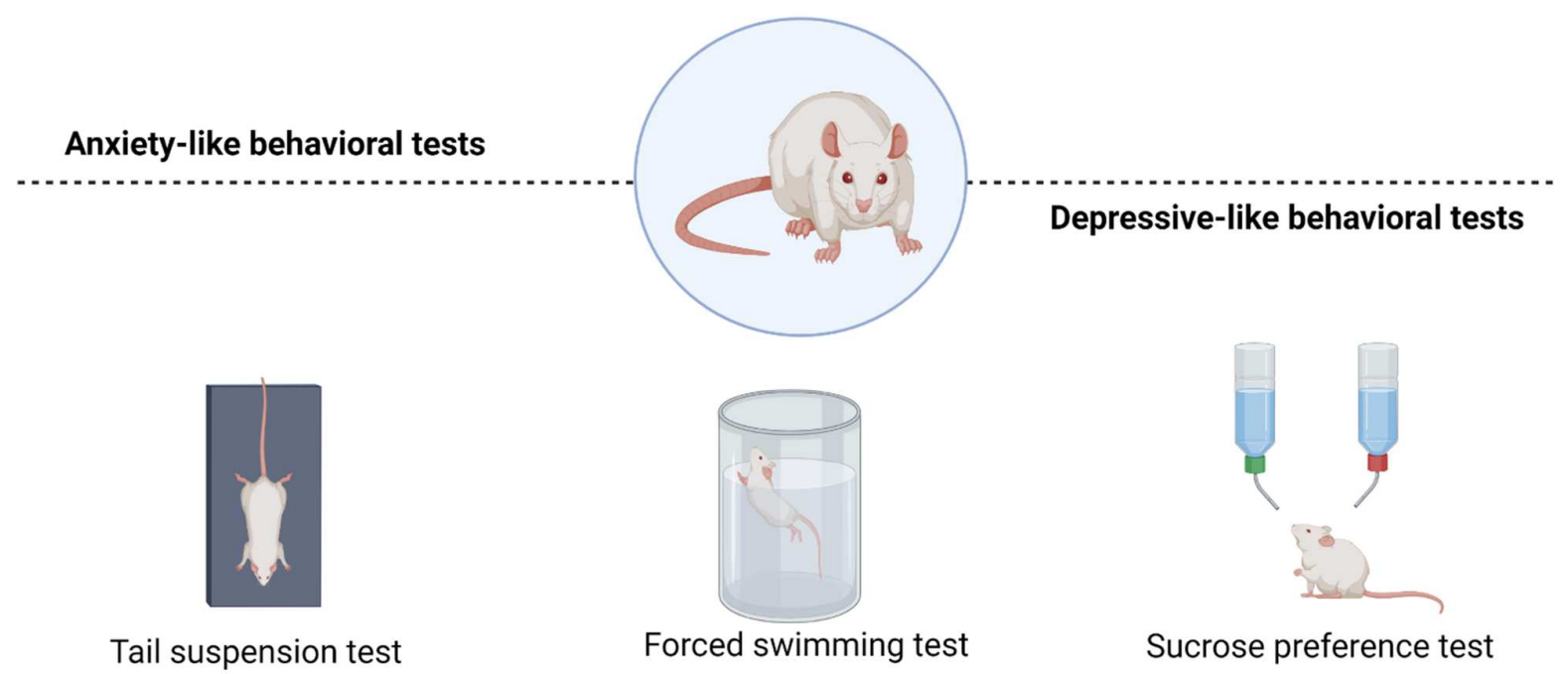

Figure 2. Behavioral tests used to study sex differences in anxiety-like and depressive-like behaviors in rodent animal models. Created with BioRender.com (accessed on: 20 December 2021).

Elevated plus maze test (EPM): The most extensively used test to analyze anxiety states exploits the natural aversion of rodents to open, elevated, and illuminated spaces. The maze consists of two walled arms opposite to two open arms, raised at around $50 \mathrm{~cm}$ from the floor. Time (usually expressed in percentage) spent in, and number of entries to, open arms is indicative of less anxiety-like behavior [31]. Compelling evidence indicates that males present less anxiety-like behavior assessed in the EPM than females. However, some studies showed that females made more open arms entries [32,33] and spent more time on the open arms of the EPM than males in unmanipulated [32,34], stressed [35], or drugtreated [36] animals. While some studies suggest a lack of estrous cycle effect [37], at least some of the sex differences observed in EPM may be attributed to activation by circulating gonadal hormones [38,39] (see below). The Elevated Zero Maze (EZM) is a circular variant of the EPM in which the disposition of open and enclosed quadrants avoids the central zone of the EPM. Some authors argue that this apparatus is better for assessing anxietylike behaviors [40], particularly because it shows more consistent behavioral outcomes in repeated trials [41].

Open field test (OFT): This test places the intrinsic exploratory nature of rodents against their aversion to open and illuminated spaces. Rodents are placed in a brightly illuminated high-walled round or square arena, and exploratory behavior is assessed usually in a $5 \mathrm{~min}$ test. The time spent in the more aversive zone of the maze (center) vs. time spent at the safer periphery (because of the rodents' known thigmotaxis) is recorded. Other variables such as total locomotion, rearing, grooming, or defecation are usually recorded too. A more anxious animal would present less exploratory behavior, more time at the periphery than in the center, less rearing, and more grooming behavior [42]. There are some conflicting results with respect to behavioral outcomes in the OFT that seem to depend on the species, strain, or the pre-evaluation treatment of the animals used. Some studies found males rearing 
more than females [43], but equivalent time in the center or exploratory behavior [37,44,45], while others found that females expressed less anxiety-like behavior than males, more exploration [32,46-48], or spent more time in the center [32,39]. The reverse was also found, with males spending more time at the center $[46,47]$.

Light-dark box test ( $L D B)$ : This test also exploits the rodents' innate exploratory behavior of novel environments and their known aversion to illuminated areas. The apparatus consists of a small dark safe compartment connected to a large illuminated aversive compartment. Time spent in each compartment is seen as indicative of the anxiety state of an animal (the more anxious, the more time in the dark safe compartment) [49]. Sex differences have been successfully addressed with LDB, and, apparently, females present less anxiety-like behavior than males [50].

Marble burying test (MBT): This test is used to measure obsessive-compulsive or repetitive behavior and anxiety-related behavior in rodents. Commonly the protocol consists of placing 10-25 marbles in a cage filled with approximately $5 \mathrm{~cm}$ deep of bedding material such as sawdust, husk, and corncob. The number of marbles that the animal buries in a fixed period (usually a $30 \mathrm{~min}$ session) are counted [51]. Although controversial, data showed that marble burying behavior is sensitive to sex hormone fluctuations along the estrous cycle in females [52,53], and when compared with males, females tended to bury fewer objects [15,54]. However, no sex differences have also been reported [55].

Forced swimming test (FST): Probably this is, by far, the most commonly used test to evaluate depressive-like behavior. The test evaluates the strategy to cope with an inescapable life-or-death situation where rodents are submerged in a recipient filled with water. Time immobile is considered as a passive coping strategy (indicative of a "behavioral despair"), while time swimming, attempts to climb, or strong leg movements (rather than small movements that aid flotation) are viewed as an active coping strategy to stay alive [56]. Despite their limited scope to recreate human anhedonia, sex differences in the FST have been widely reported but not consistently among the different studies [57]. Sex differences seem to appear after puberty, suggesting a role of gonadal hormones. Adult males show greater levels of immobility and climbing, and fewer swimming behaviors than females [58]. However, an exhaustive work with normal-cycling females showed that the effect of the estrous phase is probably small and that females exhibited higher levels of immobility than males [57]. Moreover, during the FST, other behaviors such as head swinging can be measured since this shows a marked sex difference (greater frequency in males than females) [59].

Tail suspension test (TST): This exclusively mouse test consists of hanging the animal by the tail and registering the time it remains immobile. As in the FST, the greater the time of immobility the greater is the anhedonic/depressive-like state [60]. Once again, female mice have usually been reported to present a greater immobility time than males [61], although immobility was reduced by testosterone treatment in females [54]. However, some studies have also found that males present greater immobility time than females [62-64].

Sucrose preference test (SPT): The rewarding characteristics of sweetened solutions (saccharin, sucrose, etc.) are used to evaluate the rodents' capacity to obtain pleasurable sensations. The test consists of presenting two bottles, one with water and the other with sweetened solution, and registering the preference for each. An anhedonic/depressive animal would consume less sweetened solution [65]. This test has revealed sex differences [66] in different experimental paradigms [67-69].

\section{Sex Differences under the Scope of the "Unified Model" of Brain Sexual Differentiation}

We have mentioned a great number of sex differences in the brain and behavior in animal models of anxiety and depression that have been reported in the scientific literature. The proximate factor underlying such differences is a complex and multifactorial process of brain sexual differentiation. Such differentiation relies on biological and environmental traits that interact with each other to produce, deepen, or erase sex differences within 
distinct developmental windows. The known asymmetries between males and females at genetic (i.e., sex chromosome complement, XX in females and XY in males), hormonal (i.e., perinatal and pubertal organizational vs. adult activational effects of gonadal hormones), and environmental level (i.e., sex-specific ambiences) contribute to differentiating the brain and behavior in a sex-specific manner [6] (Figure 3). This sexual differentiation of the brain is supposedly determinant in the sexually dimorphic incidence and manifestation of psychiatric disorders in the human population [7,8]. Below, we discuss sex chromosome complement, hormonal and environmental effects on sex differences in anxiety-like and depressive-like features.

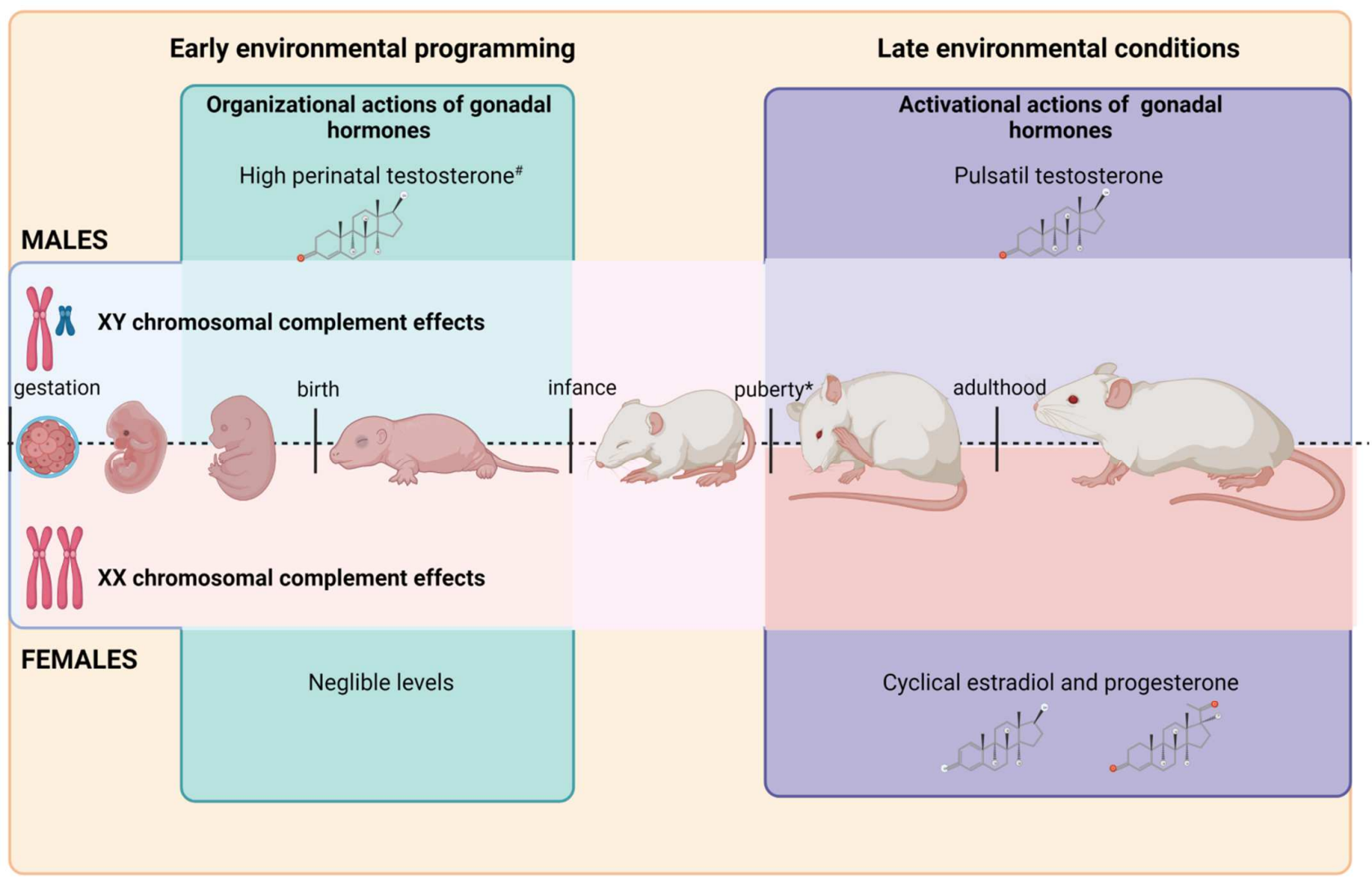

Figure 3. Unified model of sexual differentiation of brain and behavior. From gestation, sex chromosome complements orchestrate sexual differentiation of embryos by various $\mathrm{Y}$ and $\mathrm{X}$ genes. The expression of the $\mathrm{Y}$ exclusive gene Sry triggers the differentiation of bipotential gonads into testes, and their absence leads to ovaries development. Testosterone levels during the perinatal period in males (or their absence in females) interact with early environmental clues to modulate $\mathrm{Y}$ and $X$ gene expression. Later in life, environmental conditions, activational gonadal hormones actions and direct genetic factors interact on early organized circuits to induce, deepen, or erase sex differences in brain and behavior. \# Much of the testosterone actions are indeed mediated by estradiol and dihydrotestosterone metabolized in situ [70,71]. * Rapid rise of gonadal hormones at puberty has their own organizational effects [72]. Created with BioRender.com (accessed on: 20 December 2021).

Sex chromosome complement-biased sex differences: Sex chromosome complement is believed to directly affect brain structure, neurochemistry, and physiology, which may also explain the expression, development, and severity of various mental disorders [73-77]. Sex chromosome complement ( $X X$ vs. $X Y$ ) is thought to be the principal factor mediating the sexual differentiation of mammals. Very early in development, XY-bearing individuals activate a cascade of transcriptional factors that differentiate gonadal and other tissues into the male phenotype. In particular, the Y exclusive Sry gene (Sex-determining region of $\mathrm{Y}$ chromosome gene) expression promotes the differentiation of bipotential gonads to 
testes, which is responsible for the perinatal secretion of testosterone exclusive of males (see below). The absence of the Sry gene (and the action of other transcriptional factors) will in turn promote ovary development in XX-bearing individuals, developing a female phenotype. This makes it impossible to separate the contribution of sex chromosome complement from the gonadal (hormonal) contribution to sex-related traits. However, a variety of genetically modified animal models have been developed to separately assess the direct contribution of sex chromosome complement and gonadal sex to neurochemical and behavioral variables [78].

One very useful model is the Four Core Genotype (FCG) mouse in which sex chromosome complement and gonadal sex are decoupled, leading to females (with ovaries) carrying XX and XY chromosomes, and males (with testes) carrying XX and XY [79]. This enables the direct contribution of sex chromosomes, gonadal sex, and their interaction, to be assessed in every variable measured. Using the FCG, Puralewsky et al. (2016) investigated the basolateral amygdala (BLA) expression of several genes (Sst-Somatostatin, Gad67, and Gad65-Glutamic acid decarboxylase enzymes, tyrosine kinase B receptor (TrkB) — brainderived neurotrophic factor (BDNF) receptor and Bdnf-BDNF) known to be specifically dysfunctional in depressive women [80]. They demonstrated that XY prepubertal mice present a decreased expression of GABA- and BDNF-related genes compared to XX mice, irrespective of gonadal sex (testes or ovaries). Moreover, gonadectomized adults with XY chromosome complement presented decreased TrkB gene expression compared to XX individuals. Interestingly, gonadal sex and testosterone treatment also affected gene expression in the BLA. Gonadal males castrated as adults had significantly lower expression of Bdnf than gonadectomized mice that had ovaries, indicating a developmental organizational effect of gonadal hormones. Meanwhile, testosterone treatment (i.e., activational hormonal effect) produced an increase in the gene expression of Gad67 and Gad65 in gonadal males and Bdnf in gonadal females. They also investigated whether a chronic stress paradigm (known to generate anxiety/depressive-like states) affects gene expression in FCG mice and found that stressed animals with XY presented lower expression of Sst than XX individuals. Moreover, in stressed animals, testosterone treatment increased Sst expression in gonadal males compared to gonadal females for XX mice, and decreased expression in gonadal males compared to gonadal females for XY mice, but decreased Bdnf expression only in gonadal females. More importantly, there is a significant correlation between Sst/Bdnf gene expression and anxiety-like behavior, providing evidence for a direct sex chromosomal effect. These data suggest that $X Y$ individuals may present some degree of vulnerability (genetically-biased) but that this is compensated by testosterone (hormone organizational/activational-biased). The greater vulnerability of XX individuals may be due to the absence of testosterone, resulting in lower Sst expression in the amygdala [80].

Using the same mouse model, it was found that XY mice (irrespective of their gonadal status) spent more time than $X X$ mice in the dark compartment of the LDB, indicating that a more anxious state is dependent on sex chromosome complement. Meanwhile, gonadal females presented more anxiety-like behaviors than gonadal males assessed in the EPM or EZM, irrespective of their sex chromosome complement, indicating hormone organizational/activational effects [81]. Other groups failed to find a sex chromosome complement effect in OFT and EPM (canonical anxiety-like behavior tests), but diminished social behavior was found in XX mice. XX females spend a greater time digging (an asocial behavior) than all other mice, possibly indicating a genetic predisposition to a depressivelike state [82]. Gonadectomized XX mice also consumed less sweetened solution than $X Y$ mice (irrespective of whether they are males or females) in an 8-day free-access two bottle paradigm. They were also less motivated to obtain access to the reward solution in operant behavioral tests [83]. Although the authors do not discuss these results in terms of "anhedonic" behavior, a possibly depressive state may also be hypothesized and, in fact, the mice were chronically isolated to individualize sweetened solution consumption, thus exposing them to some degree of stress. If so, an $\mathrm{XX}$ chromosome complement predisposes 
to an anhedonic/depressive state, reflected by lower motivation to obtain pleasurable sensations and decreased consumption of a rewarding solution.

Some distinct depressive symptoms are manifested in men and in women. In particular, depressive women are more likely to present with anxiety and panic disorder, while higher aggression and substance use are frequently reported in depressive men [84]. Although it may be argued that this is a "culturally"-biased sex difference, there is evidence from these mice models that $X Y$ females presented more aggressive behavior than $X X$ females [85], and that an $\mathrm{XY}$ complement predicts a more rapid alcohol habit formation than XX [86], suggesting a possible sex chromosome effect in these sex-specific behaviors in depression.

By means of other mouse models, Saunders et al. (2016) [87] found that the Y chromosome affects the display of anxiety-like behaviors. The African pygmy mouse, Mus minutoides, has naturally four types of individuals with different genotypes: all males (bearing testes) are $X Y$, while females (fertile and bearing ovaries) are $X X, X^{*}$ or $X^{*} Y$, in which the asterisk represents an unknown $X$-linked mutation preventing masculinization of $X^{*} Y$ embryos. When assessed in the LDB, Y-bearing individuals ( $X Y$ males and $X^{*} Y$ females) spent less time immobile and had an enhanced exploratory behavior, indicating less anxiety-like behavior than $X X$ and $X X^{*}$ individuals [87].

The involvement of the $\mathrm{X}$ chromosome in the display of anxiety-like behavior was also demonstrated in a model of Turner's syndrome (aneuploidy of X chromosome- $\mathrm{XO}$ ). Mice with the $\mathrm{XO}$ genotype spent less time in and performed fewer entries into the open arms of EPM than XX individuals. Moreover, expression of the steroid sulfatase enzyme and $\mathrm{GABA}_{\mathrm{A}}$ receptor (GABAAR) subunit genes (all implicated in anxiolytic effects) are decreased in $\mathrm{XO}$ compared to $\mathrm{XX}$ mice. The authors argued the existence of genes on the $\mathrm{X}$ chromosome that mediate fear reactivity, and that gene dosage may be responsible for the behavioral phenotype. As XO females only possess one allele for those genes, they exhibit more anxiety-like behaviors than XX (biallelic) females [88]. This may also explain why some studies found males to present more anxiety-like behavior (one $\mathrm{X}$, one allele).

Although some discrepancies have emerged regarding the participation of sex chromosome complement in anxiety and depression-related traits, there is no doubt that at least some features of anxiety and depressive disorders may be attributed to genes in (or regulated by) sexual chromosomes. As more and better research is conducted using animal models, we will obtain more evidence on the participation of sex chromosomes in the sex differences observed in anxiety and depressive disorders in the human population.

Gonadal hormone-biased sex differences: Probably the most convincing and widespread evidence of the origin of sex differences in brain and behavior comes from the organizational and activational effects of gonadal hormones [89]. The classical hypothesis of brain sexual differentiation states that the early secretion of testosterone by the developing testes during the perinatal period is the main factor in masculinizing and defeminizing the brain. In turn, the low levels of gonadal hormones during this critical developmental period in females lead to feminization and demasculinization of the brain and behavior [90]. Interestingly, many of testosterone's organizational effects are mediated by estradiol or dihydrotestosterone (DHT), both metabolites produced in situ from testosterone by neurons and glia $[70,71]$. After the infant quiescent period, puberty marks the beginning of gonadal re-functionality with gametogenesis and sex hormone production. The great asymmetry among males and females in the kind and levels of gonadal hormones (i.e., androgens, estrogens, and progestogens), as well as the sex difference in the rate of production and secretion (i.e., pulsatile vs. cyclical), impacts perinatally organized brain circuits and exerts sex-specific activational effects. Moreover, sex steroids in the pubertal period have their own organizational effects on brain and behavior [72]. Experimental dissection of organizational vs. activational effects in laboratory animals allowed us to identify perinatal vs. adult hormonal influences on anxiety-like and depressive-like traits. In fact, sex hormones have been implicated in several characteristics of mood disorders that are expressed in a sexually dimorphic way in humans as well as in animal models $[13,91,92]$. 
Gonadal hormone exposure or its absence during the perinatal period differentially organizes brain circuits and behavior in males and females, respectively. These are enduring effects that are manifested later in life, and sex differences in brain circuitry may account for a sex-specific predisposition to mood disorders. Goel and Bale (2008) [54] examined the physiological and behavioral effects of organizational vs. activational testosterone effects in C57BL/6J mice, injecting testosterone in females at postnatal day 1 and/or ovariectomizing and later implanting testosterone capsules at postnatal day 28, respectively. They found that intact females showed higher levels of plasma corticosterone than intact males in response to restraint stress, and that activational effects of testosterone in females resulted in corticosterone decreased to levels similar to males. At the behavioral level, intact females showed greater immobility time than males in the TST, and, once again, the activational effects of testosterone in females resulted in immobility reduced to male levels. Surprisingly, females exposed to both organizational and activational testosterone were not masculinized, suggesting a chromosomal effect. In anxiety-like measures in the MBT and LDB, there were different results. Organizational or activational testosterone-treated females and males buried more marbles than intact females, while no sex differences were detected in LDB. These results suggest that anxiety- and depressive-like tasks are differentially susceptible to testosterone's organizational or activational effects [54]. Intriguingly, it has been recently reported that neonatal estradiol treatment of females increased immobility time in the FST to the same level as untreated male CF1 mice tested when adults, indicating that a sex difference in the expression of this depressive-like behavior may be attributed to the organizational effects of sex steroids [93]. Lu et al. (2016) have shown that stress induced by chronic light deprivation produced a more severe phenotype of depression in prepubertal female than in prepubertal male ICR mice, associated with a decreased intrinsic excitability of cortical neurons, indicating that the female perinatal organized brain may predispose to depressive vulnerability [61]. In a model of anxiety and depression by chronic social isolation, Carrier and Kabbaj (2012) showed that testosterone treatment has anxiolytic and antidepressant effects in castrated adult male but not in ovariectomized female Sprague Dawley rats when evaluated in the EPM, LDB, and SPT tests. Moreover, testosterone replacement and imipramine treatment also reverted the reduced cell proliferation at the dentate gyrus of the hippocampus of socially isolated castrated male rats [94].

This sexually dimorphic effect of testosterone may reflect organizational hormonal effects, as the elimination of circulating (activational) sex hormones levels unmasked the well-described anxiolytic and antidepressant effects of testosterone [92]. However, it has been reported that aged males are more anxious than aged female Lewis rats when evaluated in the EPM and OFT but not in the LDB. Indeed, prepubertal gonadectomy in males diminishes anxiety in the EPM, indicating an anxiogenic effect of testicular hormones. Moreover, acute estradiol or testosterone treatment did not affect anxiety measurements in prepubertal gonadectomized aged males [39]. This may reflect an absence of activational actions but the presence of organizational actions of gonadal hormones of the pubertal period [72]. In fact, there is evidence that anxiety and depression symptoms increase in early adolescence, particularly in girls [95], indicating that higher levels of circulating sex hormones during puberty may predispose women to developing mood disorders. Adolescent Long-Evans rats of both sexes displayed significantly greater anxiety-like behavior than adult rats, and normal-cycling females were found to display greater anxietylike behavior than male rats in both the OFT and LDB [47]. Prepubertal male and female mice did not differ in anxiety-like or depressive-like behaviors tested in the EPM, OFT, FST, or MBT, but, when tested in late adolescence, males and females presented more anxiety-like and depressive-like behaviors in the MBT and FST, and females spent less time than males in the open arms of the EPM.

Prepubertal gonadectomy differentially affects anxiety-related behaviors in males and females. Castrated males spent less time in the open arms and showed a trend toward spending less time in the center of the OFT than intact males (ovariectomy had no effect on females), while ovariectomized females buried fewer marbles than intact females (castration 
had no effect on males). These sex differences seem to indicate that the activational effects of testicular hormones tend to decrease anxiety in males, while those of ovarian hormones tend to increase anxiety in females [96]. Regarding depressive-like behavior, adult males show greater levels of immobility, climbing, and less swimming behavior than adult females and prepubertal male and female Wistar rats in the FST, which may reflect testicular hormone activational effects. Basal levels of corticosterone, testosterone, and estradiol were higher in prepubertal females, adult males, and adult females, respectively, while stress-induced corticosterone levels were higher in adult animals of both sexes but not in prepubertal animals [58].

The effect of the estrous cycle on anxiety-like behavior seems contradictory. While some studies have reported that normal-cycling females present less anxiety-like related behavior than male Wistar rats in the EPM and OFT [32] and, when assessed, a lack of estrous cycle effect in Sprague Dawley rats in the EPM [37], others have found no sex differences, and lower anxiety levels in proestrus or estradiol-treated diestrus females than in diestrus female Wistar rats [38]. Diestrus female Sprague Dawley rats exhibited less anxiety-like behavior than male rats in the EPM and lower levels of hippocampal GluR1 and CREB [31], while male C57BL/6J mice spent more time in the open arms than diestrus female mice, and no sex differences were found in BALB/cJ mice [44].

Regarding the effect of estrous cycle on depressive-like behavior, Kokras et al. (2015) [46] found that adult female Wistar rats exhibited higher levels of immobility in the FST than males, and that the phase of the estrous cycle did not affect the sex difference observed. Remarkably, they showed no association of gonadal hormones and FST behavioral performance, suggesting an organizational gonadal hormone effect [57]. Similarly, it was recently reported that, when exposed to acute stress (restraint, forced swim, and brief exposure to ether until immobile) and tested a week later, sucrose preference and the latency to socially interact were decreased in normal-cycling females but not in male Sprague Dawley rats. In contrast, stressed males showed stronger acoustic startle response and enhanced negative feedback control of corticosterone, while these were not affected in females. More importantly, these were gonadal hormone-independent effects, as gonadectomy and/or testosterone replacement had little effect and only in some measures, indicating organizational rather than activational effects [69]. It was also reported that normal-cycling C57BL/6J female mice performed many fewer rearings (i.e., were more anxious) than males in the OFT [43], and that male mice performed more entries to open arms in the EPM, spent more time in the light compartment of LDB (both indicative of a lower anxiety state), and spent more time immobile in the FST than normal-cycling female mice [45]. Normal-cycling C57BL/6J female mice exhibited greater exploratory behavior but less time in the center of the OFT than male mice; however, when subjected to a chronic unpredictable stress paradigm, both male and female mice presented greater immobility time in the FST and an increase in basal corticosterone levels. However, only stressed female mice had reduced levels of hippocampal and hypothalamic glucocorticoid receptor, and only stressed male mice had higher cytoplasmatic levels of the co-chaperone protein, FKBP51, in the cortex, indicating a sex difference in HPA axis regulation [46].

Dong et al. (2020) [67] have shown a different regulation of the HPA axis and vulnerability to developing a depressive and anxiety-like phenotype between male and normalcycling female mice after chronic isolation and restraint stress. Stressed male mice were more resistant to weight loss than stressed females but, at the same time, more quickly developed depressive-like behavior in the SPT and greater anxiety-like behavior in the OFT than stressed females. Regarding HPA hormones, there were no stress or sex differences in basal corticosterone but higher levels of ACTH in stressed females and lower levels of $\mathrm{CRH}$ in stressed and unstressed females [67].

Male and female Wistar-Kyoto rats more reliably express anxiety-like (OFT) and depressive-like behavior (FST) than Sprague Dawley rats. Indeed, normal-cycling WistarKyoto female rats exhibit more exploration than males in the OFT [48]. Peri-pubertal Sprague Dawley rats, subjected to a protocol of stress by social isolation, present sex 
differences in vulnerability to express depressive and anxiety-like behaviors. Unstressed females exhibited higher levels of depression-related behaviors than unstressed males in the FST and the learned helplessness test (LHT) and lower levels of anxiety-related behaviors on the EPM. However, chronic stress exposure differentially affected males and females, as socially isolated females decreased the time spent in open arms, while males were not affected. On the other hand, socially isolated males decreased swimming time and increased immobility time in the FST, and exhibited helplessness following both inescapable and escapable shock, while socially isolated females were not affected. These data seem to indicate a sex difference in coping with stress and a differential susceptibility to developing anxiety vs. depressive-related symptoms after chronic stress exposure [97].

Synaptic plasticity protein levels are also differentially regulated by stress and sex in distinct brain regions known to be affected in anxiety and depression. Spinophilin levels at the ventral cornus ammonis III (CA3) region of the hippocampus were decreased in stressed females but higher in stressed males, while myelin basic protein levels in the region 3 of the cingulate cortex (CG3) region of the prefrontal cortex were greater in unstressed males than unstressed females, a difference that was blunted following social isolation. On the other hand, tyrosine hydroxylase levels in the BLA were greater in unstressed females than unstressed males, but socially isolated males increased the levels to the female value [97]. As stated above (see Sex chromosome complement-biased sex differences section), gonadal sex and testosterone treatment also affected gene expression of neurotransmission and neurotrophin machinery in the BLA of male and female mice, reflecting the effects of organizational and activational sex steroids [80]. In fact, sex-dependent opposite effects of social isolation were also recently found in mice [68]. While stressed males showed decreased excitability of dorsal raphe's serotonin neurons, stressed females showed greater excitability. Similarly, while stressed male mice showed more depressive-like behaviors in the FST, SP, and novelty suppressed feeding test, female mice did not present this effect. Interestingly, this experimental paradigm seems to have a greater effect on depressive-like than on anxiety-like behaviors (no differences were recorded in the EPM, LDB, or OFT) [68].

Despite some studies finding sex differences in one direction or another in anxiety and depression-related measurements, there seems to be sufficient evidence to indicate that organizational effects of gonadal hormones are a key mediator in the expression of anxiety and depressive-like behaviors later in life. It has also been reported that the activational effects of gonadal hormones play a part in the expression of anxiety and depressionrelated traits, although acting on sex-specific organized brains. Moreover, the estrous cycle effect (when assessed in large samples of animals) seems to be slight, indicating that sex differences are more reliably explained by the genetic and hormone's organizational effects. Many of the conflicting and inconsistent results between research groups may reflect the great variability in measuring, inducing, and recording anxious or depressive animal states. All this evidence suggests that inconsistencies reported in anxiety- and depressive-like sex differences are probably dependent on the variability of the species, strain, age, or treatment of the animal model used by each group. However, perinatal exposure to gonadal hormones or their absence seems to have a strong effect in later manifestations of an anxiety and depressive phenotype.

Environmentally-biased sex differences: It is widely recognized that emotional disorders such as depression, anxiety, and post-traumatic stress disorder are more frequent in women than in men $[95,98,99]$. However, the neurobiological basis of these sex differences remains unclear. To fully understand the underlying neurobiology of sex differences in stress-related vulnerability to disease, the development of appropriate animal models has been critical, particularly models based on ethologically significant environmental conditions, such as exposure to stressful situations at different moments in life. Thus, what can animal models based on environmental influences tell us about the biological basis of sex differences in regulating emotional responses? The following sections review the main contributions of the literature to this question. 
Early life programming-Intrauterine environment. Among the many environmental factors that influence the development of sex differences in the expression of emotional illnesses such as anxiety and depression, the intrauterine environment plays a fundamental role. The gestational environment regulates brain development and plays a critical role in the physiology and behavior of the offspring. Various studies in animal models suggest that gestational stress affects males and females differently, conditioning a sex-specific susceptibility to neuropsychiatric disorders, including depression and anxiety $[15,100,101]$. Animal evidence suggests that prenatal stress programs fetal brain development in a sex-specific manner that persists into adolescence and adulthood. Regarding the effects of gestational stress on anxiety and depressive-like behaviors, it has been reported that prepubertal male rats are more anxious and show depressive-like behavior in the OFT and FST, suggesting that females are more resilient to prenatal stress [102]. Similarly, stress during pregnancy has been associated with depressive-like behavior in the FST in males only in adulthood [103]. However, in other studies of prenatal stress as a rodent model for developing affective disorders in adulthood, it has been reported that female offspring showed depressive-like behavior in the FST but not anxiety-like behavior, indicating that this model may be useful for examining the mechanisms of females' propensity to develop depression [104]. Similarly, other findings suggest that prenatally stressed females are more vulnerable than males to the effects of stress during gestation as they exhibit more depressive-like behavior in the FST [105]. Although sometimes contradictory, compelling evidence from different laboratories shows that prenatal stress increases anxiety-like and depressive-like behaviors [106,107].

Prenatal stress regulates emotional responses in a sex-dependent manner, probably by programming the HPA axis and stress response development. Sex-dependent programming effects in depression and/or anxiety outcomes are proposed to be related to sex-specific timing of relevant developmental processes during pregnancy. Differences in exposure to the testosterone that the male fetus begins to produce during the gestational stage, which determines the differentiation of the genitalia, brain, and other tissues during gestation, also appear to have behavioral significance in emotional responses later in life [108]. It has also been investigated as to whether sex differences in epigenetic reprogramming may explain sex differences observed in rats exposed to prenatal stress. Lei found that exposure to prenatal stress increased anxiety-like behavior in female offspring, while male offspring exhibited more depressive-like behavior. Sex-specific epigenetic differences were observed, such as the methylation pattern in the promoter region of the GR gene, and changes in the expression of deoxyribonucleic acid (DNA) methyltransferase and DNA demethylase [109].

Despite some inconsistencies, clinical studies generally support the evidence provided by animal models $[25,110,111]$. A recent review addressing sex differences in vulnerability to prenatal stress in children's health, reports evidence of sex-dependent outcomes of prenatal exposure to stress, and that the different strategies of male and female fetuses to cope with prenatal stress give females greater viability, but increase their vulnerability to psychiatric illnesses [108]. As in other studies of early programming of physiological systems, while the gestational stress model has permitted controlled experiments, the nature of the stress, and the duration and timing of stress exposure during the gestational period are important elements to consider when evaluating the emotional outcomes.

In sum, the prenatal stress model is useful in elucidating sexually dimorphic epigenetic mechanisms that underlie the consequences of gestational stress as a trigger for emotional disorders such as anxiety and depression later in life. However, the model presents some limitations. In terms of sex differences, the results are inconsistent so far. There is also some uncertainty regarding the predictive validity of pharmacological treatments, and, finally, there are known to be large differences in the ontogenetic development of the CNS between rodents and humans, which make it difficult to extrapolate the results.

Early life programming - postnatal environment. Early postnatal environment is an important period characterized by a high neuroendocrine plasticity. Early life stress has been demonstrated to be associated with many psychological disorders including depression 
and anxiety. Consistent evidence suggests that greater vulnerability to affective disorders after exposure to stress early in life is associated with hyperactivation of the HPA axis and an imbalance in the corticosteroid receptors (GR and MR) in the brain [112]. Moreover, findings from both animal studies and clinical research indicate that early life exposure to stress impacts the functional development of amygdala-prefrontal circuitry, which is implicated in threat reactivity and emotion regulation and has been shown to be highly sensitive to early life stress [113]. However, the sexually dimorphic consequences of early life stress in relation to mental illnesses have not been studied.

Since the mother-pup pair forms an interdependent dyad, the disruption of their interaction generates serious consequences, resulting in alterations in development, growth, physiology, and behavior. In rodent pups, the first two weeks of life represent a critical developmental period called the "stress hyporesponsive period" (SHRP), during which there is a marked decrease in stress response. In animal models, early life stress, such as maternal separation (MS) during the SHRP, dysregulated hypothalamic-pituitary-adrenal (HPA) axis development and increased vulnerability to emotional disorders later in life in a sex-dependent manner $[114,115]$. Other models of early stress that increase vulnerability to psycho-affective illness include the chronic social instability stress [116], early weaning [117], limited bedding material paradigms [118,119], and post-weaning social isolation stress [120].

MS significantly increased depressive-like behavior in adolescent female mice and altered spatial memory in adolescent male mice, as well as changes in hippocampal microglia and synaptic gene expression [121]. Other studies reported that MS caused depressive-like and anxiety-like behaviors in rats but did not find significant differences in sex effects, suggesting that gender factors may not be an important factor for depression in the rodent model of maternal separation [122].

The rat MS model has shown that this paradigm increases vulnerability to chronic stress exposure later in life in a sexually dimorphic manner, but there are inconsistencies in the literature. Prolonged MS promotes behavioral resilience of female rats to adult stress re-exposure in the OFT, while it increases the vulnerability of male rats to adult stress re-exposure, but no differences were observed in the FST [123]. On the other hand, it was reported that, with MS at an early age and chronic unpredictable mild stress in adolescence, adult female rats showed very intense depressive-like and anxiety-like phenotypes [124]. Similarly, exposure to early-life stress had significant female-specific impact in terms of anxiety- and depression-related behaviors, suggesting that early-life stress disrupts the protective role of estrogen in females and promotes female vulnerability to the anxiety- and depression-related phenotypes associated with low estrogen. Plausible transcriptional and epigenetic alterations in psychiatric risk genes were proposed $[125,126]$.

When testing the effect of early life stress in the form of limited bedding material on affective behavioral outcomes in both male and female mice, it was reported that, during early adolescence and adulthood, only females went on to develop depressive-like behaviors, and that these symptoms may be resolved with the fast-acting antidepressant, ketamine [119]. This model led to fragmented maternal behavior that induced a depressivebut not anxiety-like phenotype in early stress-exposed females.

Although the MS model has been widely used, most of the results come from studies in males $[127,128]$. The main weakness of this model in terms of emotional and sexually dimorphic consequences is that it has methodological pitfalls that may influence the reliability of its results. This paradigm increases vulnerability to suffer from emotional disorders, including anxiety and depression in both adolescence and adulthood. Studies analyzing sex bias frequently indicate that females are more prone to anxiety behaviors, particularly when the EPM is used.

Adult Stress Exposure-Chronic Variable Stress model. Many of the animal models of affective disorders involve chronic exposure to stress. The chronic variable stress model (also named chronic mild stress and chronic unpredictable mild stress) is one of the most extensively used in preclinical studies to induce depressive-like behavior. In this model, 
rodents (rats or mice) are exposed sequentially, over a period of weeks, to a variety of mild stressors, usually presented unpredictably. Under this paradigm, in the FST, EPM, and SPT, animals develop neurochemical and neurobehavioral aspects of both anxietyand depressive-like behaviors. It has been used by various laboratories and is, overall, a widely-validated model of depression (meeting construct validity, face validity, and predictive validity criteria) [17]. As in other preclinical research, relatively few studies have examined sex differences in the response to the variable chronic stress paradigm.

Both male and female rats have been shown to increase anhedonic-like behavior in the sweet drive test, which combined analysis of food preference with ultrasonic vocalizations [129]. Studies from different laboratories suggest that exposure to chronic mild stress increased anhedonic behavior in both sexes, with a more pronounced response in males than females [130-132]. Other studies, however, found that female rats appear more vulnerable to chronic mild stress exposure and showed a more robust anhedonic response [133-135]. The results of using a congenital 5-HT deficient mouse model to investigate the impact of sex on susceptibility to chronic stress demonstrate that females are more susceptible to behavioral despair induced by chronic mild stress in the FST. In addition, female mice exhibited an overall increase in anxiety-like behavior, but no differences were found in sucrose preference [136].

Sex differences in neurochemical and neuroendocrine responses to chronic mild stress have been reported, including a decrease in hippocampal serotonergic activity and a decrease in cortical dopaminergic activity in females but not in males [130,131], which may account for the sexually dimorphic behavioral responses.

Despite inconsistencies, the chronic mild stress paradigm has been successfully used to assess sex differences in the field of anxiety and depression. Male and female rodents seem to respond differently to chronic mild stress exposure, depending on the behavioral test used to measure emotional outcomes, physiological conditions, and neurobiological parameters, including age, hormonal status, and the duration and type of the stressors [137].

Adult Stress exposure-Acute stress. The learned helplessness model is widely used to induce depressive-like and anxiety-like states. This paradigm consists of applying inescapable stress (generally an electric shock), after which the animals are unable to cope with aversive but escapable contingencies. There is little evidence regarding sex differences using this acute stress model, but studies have demonstrated the importance of considering both genetic background and sex differences when analyzing the behavioral consequences of the learned helplessness paradigm in mice [138]. Other studies indicate that female rats recover from the shock faster than male rats during training and maintain escape-seeking behavior. Thus, extinction of the avoidance behavior occurs more slowly, which may be interpreted as females being more resilient than males [131,139]. Other results suggest a role for gonadal hormones in the development of learned helplessness in female and male rats [140]. However, other studies have reported no effects of the estrous cycle in learned helplessness behavior [131,141]. Bland et al. (2005) [142] tested sex differences in the learned helplessness model and found that, immediately following inescapable stress, male rats display a greater increase in both c-fos and BDNF mRNA expression in the prefrontal cortex than females. In contrast, one hour after inescapable shock, expression levels of both genes were either similar in both sexes or higher in females than in males. These findings suggest differential temporal response patterns in males and females [142].

Adult Stress exposure-psychosocial stress. Other well-established rodent models of depression and anxiety that involve exposure to stress during adulthood, such as the models of psychosocial stress frequently used in males to induce anxiety and depression phenotypes, have been little explored in females or in studies that address sex differences due to the fact that rodent females in general are much less aggressive and less territorial and do not establish social hierarchies $[143,144]$. Social instability, on the other hand, is presented as a socially ethologically relevant stress model to induce emotional disorder in females, which may have relevance for studies of sexually dimorphic responses. This model combines periods of social isolation, overcrowding, and changing cage mates, disrupting 
social networks. As the model is not standardized among the different laboratories, there is great variability in the reported outcomes $[145,146]$. In general, females exposed to the social instability stress paradigm present anxiety-like and depressive-like behavior as well as neurobiological characteristics associated with emotional disorders $[147,148]$. Regarding sex differences, it has been reported that this stress model negatively affects the performance of both males and females in the OFT, LDB, and novelty suppressed feeding tests, increases immobility in the FST, and activates the HPA axis [149].

Since rodents are social animals and display a complex series of social play behavior, ultrasonic communication, and social learning behaviors, social isolation (defined as lack of social contact) is stressful and has been proposed as a model for emotional disturbances [18] Prolonged social isolation causes both anxiety-like and depressive-like behavior in male rats, indicated by their avoiding the central zone in the OFT and prolonged immobility in the FST [150]. Isolated male rats also showed a reduction in sucrose consumption [151]. These alterations occur in parallel with neuromolecular and neuroendocrine changes. Regarding sex differences, results indicate a sex-specific impact on the effects of social stress in adolescence. Isolated female rats exhibited active coping behavior in the FST and showed an increased sucrose preference, while no effects were observed in male rats $[151,152]$. Similarly, other studies reported chronic social isolation stress differentially affecting the neuroendocrine stress response in male and female rats. Socially isolated male, but not female, rats displayed depressive-like behavior and higher hippocampal BDNF [151], and social isolation produced an anxiogenic profile in the EPM in males but not in females [153]. However, conflicting results were reported about the stress response in socially isolated animals in which isolated female rats exhibited stronger adrenal responses to stress and increased hypothalamic vasopressin mRNA and BDNF mRNA in the hippocampus compared with male rats, which also exhibited a reduced state of anxiety in the EPM [154].

Mood disorders are more common in women than in men, but in a large number of studies, female rodents displayed less anxiety-like and depressive-like behavior. One explanation for this discrepancy may be that males and females have very distinct response profiles to stress, reflecting environmentally-biased sex differences. As the type of stressor has been shown to have a role in triggering anxiety and depression in humans [14,155], it is not surprising that male and female rodents are differentially affected by the stress paradigm used by researchers. The kind of test used to assess depressive and anxious states in rodents may also contribute to explaining contradictory results as males and females have different strategies to cope with novel environments [156].

\section{Conclusions}

There is no doubt that there are sex differences in anxiety and depression in the human population. There is, also, no doubt that biological and cultural factors exert profound effects on the incidence of mood disorders in men and women. We have addressed sex differences in anxiety-like and depressive-like features found in animal models under the scope of the unified model of sexual differentiation. A differential genetic background, different types, times, and levels of sex hormone exposure, and different environmental conditions interact, and may result in disparities in male and female vulnerability to anxiety and depression. Evidence seems to indicate that an X chromosome complement would have some influence on inducing an anxiety-like and depressive-like phenotype $[82,83,88]$. Moreover, Y chromosome would mediate a specific behavioral phenotype $[85,86]$ that parallels some symptoms of depressive men [84]. However, as we have stated above, genes interact with other factors that regulate their expression and, intriguingly, interactions have been reported to influence these mood disorder-like behaviors [81,84]. Environmental conditions and sex hormones milieus during the perinatal period have been demonstrated to induce programming of anxiety-like and depressive-like behaviors, effects that differentially affect males and females. While some evidence shows a certain resilience to perinatal aversive situations in females compared to males [102,103,123], other evidence 
shows the opposite $[104,105,119,121]$. Perinatal exposition to gonadal hormones in males has been inversely associated with later development of anxiety and depressive-like phenotype $[61,69,94,125,126]$. However, some evidence seems to indicate the contrary [68,93]. HPA axis responsiveness and limbic areas of the brain are particularly sensitive to environmental and hormonal influences during this period and later conditions exert differential responses in males and females. The rapid pubertal rise of gonadal hormones has been implicated in trigger mood disorders, especially in girls [95]. Evidence supported by animal models shows that adolescence is also a critical period to developing anxiety-like and depressive-like states, particularly in females $[47,96]$. During adulthood, activational actions of gonadal hormones also have influence in the expression of anxiety and depressiverelated traits, although acting on sex-specific organized brains [13,91,92]. In fact, different adult environmental conditions can increase or decrease male and female vulnerability to the development of anxiety and depressive-like states [137], reflecting the complex nature of the interactions between genes, hormones, and ambience in the early programming of future responses.

To better understand sex differences in mood disorders, more preclinical studies must include individuals of both sexes when investigating the underlying biological mechanisms and testing new treatments for anxiety and depression. Moreover, evidence reviewed here reveals that "biological sex" is a determining factor in the incidence of anxiety and depression. The clinical importance of this relies not only on sex differences in the incidence and severity of mood disorders' manifestation, but also on the fact that men and women have different sensitivity to pharmacological treatments. While women seem to respond more favorably to selective serotonin reuptake inhibitors, men do so to tricyclic antidepressants [157-159]. Investigating sex differences in preclinical research could promote the development of more accurate pharmacological treatments for both men and women suffering from anxiety and depression. Despite their limited scope to reveal the ultimate factors mediating sex differences in mood disorders, animal models have much to tell us about this issue.

Author Contributions: Conceptualization, investigation, writing-original draft preparation, writingreview and editing, F.R.M. and M.A.R. All authors have read and agreed to the published version of the manuscript.

Funding: This research was funded by CONICET, grant number PIP 2021-2023 No 11220200102134 CO and the Secretary of Science and Technology (SeCyT) of National University of Cordoba (UNC), Consolidar Program, Grant Res. 411-18, No 00-10460/2015.

Institutional Review Board Statement: Not applicable.

Informed Consent Statement: Not applicable.

Conflicts of Interest: The authors declare no conflict of interest. The funders had no role in the design of the study; in the collection, analyses, or interpretation of data; in the writing of the manuscript, or in the decision to publish the results.

\section{References}

1. Salk, R.H.; Hyde, J.S.; Abramson, L.Y.; Hyde, J.S.; Abramson, L.Y. Gender differences in depression in representative national samples: Meta-analyses of diagnoses and symptoms. Psychol. Bull. 2017, 143, 783-822. [CrossRef]

2. Bekker, M.H.J.; van Mens-Verhulst, J. Anxiety Disorders: Sex Differences in Prevalence, Degree, and Background, But GenderNeutral Treatment. Gend. Med. 2007, 4, S178-S193. [CrossRef]

3. World Health Organization. Depression and Other Common Mental Disorders: Global Health Estimates; World Health Organization: Geneva, Switzerland, 2017.

4. McCarthy, M.M.; Arnold, A.P.; Ball, G.F.; Blaustein, J.D.; de Vries, G.J. Sex differences in the brain: The not so inconvenient truth. J. Neurosci. 2012, 32, 2241-2247. [CrossRef]

5. Miller, L.R.; Marks, C.; Becker, J.B.; Hurn, P.D.; Chen, W.J.; Woodruff, T.; McCarthy, M.M.; Sohrabji, F.; Schiebinger, L.; Lee Wetherington, C.; et al. Considering sex as a biological variable in preclinical research. FASEB J. 2017, 31, 29-34. [CrossRef] [PubMed]

6. McCarthy, M.M.; Arnold, A.P. Reframing sexual differentiation of the brain. Nat. Neurosci. 2011, 14, 677-683. [CrossRef] 
7. Bangasser, D.A.; Valentino, R.J. Sex differences in stress-related psychiatric disorders: Neurobiological perspectives. Front. Neuroendocrinol. 2014, 35, 303-319. [CrossRef]

8. Kokras, N.; Dalla, C. Sex differences in animal models of psychiatric disorders. Br. J. Pharmacol. 2014, 171, 4595-4619. [CrossRef]

9. American Psychiatric Association. Diagnostic and Statistical Manual of Mental Disorders, 5th ed.; American Psychiatric Pub: Washington, DC, USA, 2013.

10. Nestler, E.J.; Hyman, S.E. Animal models of neuropsychiatric disorders. Nat. Neurosci. 2010, 13, 1161-1169. [CrossRef] [PubMed]

11. Belzung, C.; Lemoine, M. Criteria of validity for animal models of psychiatric disorders: Focus on anxiety disorders and depression. Biol. Mood Anxiety Disord. 2011, 1, 1-14. [CrossRef] [PubMed]

12. Salgado, J.V.; Sandner, G. A critical overview of animal models of psychiatric disorders: Challenges and perspectives. Rev. Bras. Psiquiatr. 2013, 35 (Suppl. 2), 77-81. [CrossRef]

13. Eid, R.S.; Gobinath, A.R.; Galea, L.A.M. Sex differences in depression: Insights from clinical and preclinical studies. Prog. Neurobiol. 2019, 176, 86-102. [CrossRef] [PubMed]

14. Angst, J.; Gamma, A.; Gastpar, M.; Lépine, J.P.; Mendlewicz, J.; Tylee, A. Gender differences in depression: Epidemiological findings from the European DEPRES I and II Studies. Eur. Arch. Psychiatry Clin. Neurosci. 2002, 252, 201-209. [CrossRef] [PubMed]

15. Goel, N.; Bale, T.L. Examining the intersection of sex and stress in modelling neuropsychiatric disorders. J. Neuroendocrinol. 2009, 21, 415-420. [CrossRef] [PubMed]

16. Vetulani, J. Early maternal separation: A rodent model of depression and a prevailing human condition. Pharmacol. Rep. 2013, 65, 1451-1461. [CrossRef]

17. Willner, P. The Chronic Mild Stress (CMS) model of depression: History, evaluation and usage. Neurobiol. Stress 2017, 6, 78-93 [CrossRef] [PubMed]

18. Mumtaz, F.; Khan, M.I.; Zubair, M.; Dehpour, A.R. Neurobiology and consequences of social isolation stress in animal model-A comprehensive review. Biomed. Pharmacother. 2018, 105, 1205-1222. [CrossRef]

19. Wang, L.; Hou, W.; He, Z.; Yuan, W.; Yang, J.; Yang, Y.; Jia, R.; Zhu, Z.; Zhou, Y.; Tai, F. Effects of chronic social defeat on social behaviors in adult female Mandarin Voles (Microtus Mandarinus): Involvement of the oxytocin system in the nucleus accumbens. Prog. Neuro-Psychopharmacol. Biol. Psychiatry 2018, 82, 278-288. [CrossRef]

20. Maier, S.F.; Seligman, M.E.P. Learned helplessness at fifty: Insights from neuroscience. Psychol. Rev. 2016, 123, 349-367. [CrossRef]

21. Abelaira, H.M.; Reúus, G.Z.; Quevedo, J. Animal models as tools to study the pathophysiology of depression. Rev. Bras. Psiquiatr. 2013, 35 (Suppl. 2), 112-120. [CrossRef]

22. Krishnadas, R.; Cavanagh, J. Depression: An inflammatory illness? J. Neurol. Neurosurg. Psychiatry 2012, 83, 495-502. [CrossRef]

23. Planchez, B.; Surget, A.; Belzung, C. Animal models of major depression: Drawbacks and challenges. J. Neural. Transm. 2019, 126, 1383-1408. [CrossRef] [PubMed]

24. Nandam, L.S.; Brazel, M.; Zhou, M.; Jhaveri, D.J. Cortisol and major depressive disorder-Translating findings from humans to animal models and back. Front. Psychiatry 2020, 10, 1-15. [CrossRef] [PubMed]

25. El Yacoubi, M.; Vaugeois, J.M. Genetic rodent models of depression. Curr. Opin. Pharmacol. 2007, 7, 3-7. [CrossRef]

26. Urani, A.; Chourbaji, S.; Gass, P. Mutant mouse models of depression: Candidate genes and current mouse lines. Neurosci. Biobehav. Rev. 2005, 29, 805-828. [CrossRef]

27. Renoir, T.; Pang, T.; Hannan, A. Effects of environmental manipulations in genetically targeted animal models of affective disorders. Neurobiol. Dis. 2013, 57, 12-27. [CrossRef] [PubMed]

28. Czéh, B.; Fuchs, E.; Wiborg, O.; Simon, M. Animal models of major depression and their clinical implications. Prog. NeuroPsychopharmacol. Biol. Psychiatry 2016, 64, 293-310. [CrossRef]

29. Biselli, T.; Lange, S.S.; Sablottny, L.; Steffen, J.; Walther, A. Optogenetic and chemogenetic insights into the neurocircuitry of depression-like behaviour: A systematic review. Eur. J. Neurosci. 2021, 53, 9-38. [CrossRef]

30. Muir, J.; Lopez, J.; Bagot, R.C. Wiring the depressed brain: Optogenetic and chemogenetic circuit interrogation in animal models of depression. Neuropsychopharmacology 2019, 44, 1013-1026. [CrossRef]

31. Kraeuter, A.-K.; Guest, P.C.; Sarnyai, Z. The elevated plus maze test for measuring anxiety-like behavior in rodents. In Pre-Clinical Models. Methods in Molecular Biology; Guest, P., Ed.; Humana Press: New York, NY, USA, 2019; Volume 1916, pp. 56-74.

32. Knight, P.; Chellian, R.; Wilson, R.; Behnood-Rod, A.; Panunzio, S.; Bruijnzeel, A.W. Sex differences in the elevated plus-maze test and large open field test in adult wistar rats. Pharmacol. Biochem. Behav. 2021, 204, 173168. [CrossRef]

33. Belviranli, M.; Atalik, K.E.N.; Okudan, N.; Gökbel, H. Age and sex affect spatial and emotional behaviors in rats: The role of repeated elevated plus maze test. Neuroscience 2012, 227, 1-9. [CrossRef]

34. Xiang, X.; Huang, W.; Haile, C.N.; Kosten, T.A. Hippocampal GluR1 associates with behavior in the elevated plus maze and shows sex differences. Behav. Brain Res. 2011, 222, 326-331. [CrossRef] [PubMed]

35. Renard, G.M.; Suárez, M.M.; Levin, G.M.; Rivarola, M.A. Sex differences in rats: Effects of chronic stress on sympathetic system and anxiety. Physiol. Behav. 2005, 85, 363-369. [CrossRef] [PubMed]

36. Albrechet-Souza, L.; Schratz, C.L.; Gilpin, N.W. Sex differences in traumatic stress reactivity in rats with and without a history of alcohol drinking. Biol. Sex Differ. 2020, 11, 1-11. [CrossRef] [PubMed]

37. Scholl, J.L.; Afzal, A.; Fox, L.C.; Watt, M.J.; Forster, G.L. Sex differences in anxiety-like behaviors in rats. Physiol. Behav. 2019, 211, 112670. [CrossRef] [PubMed] 
38. Marcondes, F.K.; Miguel, K.J.; Melo, L.L.; Spadari-Bratfisch, R.C. Estrous cycle influences the response of female rats in the elevated plus-maze test. Physiol. Behav. 2001, 74, 435-440. [CrossRef]

39. Domonkos, E.; Borbélyová, V.; Csongová, M.; Bosý, M.; Kačmárová, M.; Ostatníková, D.; Hodosy, J.; Celec, P. Sex differences and sex hormones in anxiety-like behavior of aging rats. Horm. Behav. 2017, 93, 159-165. [CrossRef]

40. Kulkarni, S.; Singh, K.; Bishnoi, M. Elevated Zero-Maze: A paradigm to evaluate anti-anxiety effects of drugs. Methods Find Exp. Clin. Pharm. 2007, 29, 343-348.

41. Tucker, L.B.; McCabe, J.T. Behavior of male and female C57Bl/6J mice is more consistent with repeated trials in the elevated zero maze than in the elevated plus maze. Front. Behav. Neurosci. 2017, 11, 1-8. [CrossRef]

42. Kraeuter, A.-K.; Guest, P.C.; Sarnyai, Z. The open field test for measuring locomotor activity and anxiety-like behavior. In Pre-Clinical Models. Methods in Molecular Biology; Guest, P.C., Ed.; Humana Press: New York, NY, USA, 2019; Volume 1916, pp. 99-103.

43. Sturman, O.; Germain, P.L.; Bohacek, J. Exploratory rearing: A context-and stress-sensitive behavior recorded in the open-field test. Stress 2018, 21, 443-452. [CrossRef]

44. An, X.L.; Zou, J.X.; Wu, R.Y.; Ying, Y.; Tai, F.D.; Zeng, S.Y.; Rui, J.; Xia, Z.; Liu, E.Q.; Hugh, B. Strain and sex differences in anxiety-like and social behaviors in C57Bl/6J and BALB/CJ mice. Exp. Anim. 2011, 60, 111-123. [CrossRef]

45. Carreira, M.B.; Cossio, R.; Britton, G.B. Individual and sex differences in high and low responder phenotypes. Behav. Processes 2017, 136, 20-27. [CrossRef]

46. Palumbo, M.C.; Dominguez, S.; Dong, H. Sex differences in hypothalamic-pituitary-adrenal axis regulation after chronic unpredictable stress. Brain Behav. 2020, 10, 1-10. [CrossRef] [PubMed]

47. Bishnoi, I.R.; Ossenkopp, K.P.; Kavaliers, M. Sex and age differences in locomotor and anxiety-like behaviors in rats: From adolescence to adulthood. Dev. Psychobiol. 2021, 63, 496-511. [CrossRef]

48. Burke, N.N.; Coppinger, J.; Deaver, D.R.; Roche, M.; Finn, D.P.; Kelly, J. Sex differences and similarities in depressive- and anxiety-like behaviour in the Wistar-Kyoto Rat. Physiol. Behav. 2016, 167, 28-34. [CrossRef] [PubMed]

49. Bourin, M.; Hascoët, M. The Mouse Light/Dark Box Test. Eur. J. Pharmacol. 2003, 463, 55-65. [CrossRef]

50. De Oliveira Sergio, T.; Wetherill, L.; Kwok, C.; Khoyloo, F.; Hopf, F.W. Sex differences in specific aspects of two animal tests of anxiety-like behavior. Psychopharmacology 2021, 238, 2775-2787. [CrossRef]

51. Deacon, R.M.J. Digging and marble burying in mice: Simple methods for in vivo identification of biological impacts. Nat. Protoc. 2006, 1, 122-124. [CrossRef] [PubMed]

52. Schneider, T.; Popik, P. Attenuation of estrous cycle-dependent marble burying in female rats by acute treatment with progesterone and antidepressants. Psychoneuroendocrinology 2007, 32, 651-659. [CrossRef]

53. Llaneza, D.C.; Frye, C.A. Progestogens and estrogen influence impulsive burying and avoidant freezing behavior of naturally cycling and ovariectomized rats. Pharmacol. Biochem. Behav. 2009, 93, 337-342. [CrossRef]

54. Goel, N.; Bale, T.L. Organizational and activational effects of testosterone on masculinization of female physiological and behavioral stress responses. Endocrinology 2008, 149, 6399-6405. [CrossRef]

55. Taylor, G.T.; Lerch, S.; Chourbaji, S. Marble burying as compulsive behaviors in male and female mice. Acta Neurobiol. Exp. 2017, 77, 254-260. [CrossRef]

56. Slattery, D.A.; Cryan, J.F. Using the rat forced swim test to assess antidepressant-like activity in rodents. Nat. Protoc. 2012, 7, 1009-1014. [CrossRef] [PubMed]

57. Kokras, N.; Antoniou, K.; Mikail, H.G.; Kafetzopoulos, V.; Papadopoulou-Daifoti, Z.; Dalla, C. Forced Swim Test: What about females? Neuropharmacology 2015, 99, 408-421. [CrossRef] [PubMed]

58. Martínez-Mota, L.; Ulloa, R.E.; Herrera-Pérez, J.; Chavira, R.; Fernández-Guasti, A. Sex and age differences in the impact of the forced swimming test on the levels of steroid hormones. Physiol. Behav. 2011, 104, 900-905. [CrossRef]

59. Kokras, N.; Polissidis, A.; Antoniou, K.; Dalla, C. Head Shaking in the Forced Swim Test: A robust but unexplored sex difference Pharmacol. Biochem. Behav. 2017, 152, 90-96. [CrossRef]

60. Can, A.; Dao, D.T.; Terrillion, C.E.; Piantadosi, S.C.; Bhat, S.; Gould, T.D. The Tail Suspension Test. J. Vis. Exp. 2011, 58, 2-7. [CrossRef] [PubMed]

61. Lu, C.; Wang, Y.; Zhang, Y.F. Light deprivation produces a sexual dimorphic effect on neural excitability and depression-like behavior in mice. Neurosci. Lett. 2016, 633, 69-76. [CrossRef] [PubMed]

62. Andreasen, J.T.; Redrobe, J.P. Antidepressant-like effects of nicotine and mecamylamine in the mouse forced swim and tail suspension tests: Role of strain, test and sex. Behav. Pharmacol. 2009, 20, 286-295. [CrossRef] [PubMed]

63. Jones, M.D.; Lucki, I. Sex differences in the regulation of serotonergic transmission and behavior in 5-HT receptor knockout mice. Neuropsychopharmacology 2005, 30, 1039-1047. [CrossRef]

64. Liu, N.; Wang, Y.; An, A.Y.; Banker, C.; Qian, Y.H.; O'Donnell, J.M. Single housing-induced effects on cognitive impairment and depression-like behavior in male and female mice involve neuroplasticity-related signaling. Eur. J. Neurosci. 2020, 52, 2694-2704. [CrossRef]

65. Liu, M.Y.; Yin, C.Y.; Zhu, L.J.; Zhu, X.H.; Xu, C.; Luo, C.X.; Chen, H.; Zhu, D.Y.; Zhou, Q.G. Sucrose preference test for measurement of stress-induced anhedonia in mice. Nat. Protoc. 2018, 13, 1686-1698. [CrossRef] [PubMed]

66. Sclafani, A.; Hertwig, H.; Vigorito, M.; Feigin, M.B. Sex differences in polysaccharide and sugar preferences in rats. Neurosci. Biobehav. Rev. 1987, 11, 241-251. [CrossRef] 
67. Dong, Y.; Wang, X.; Zhou, Y.; Zheng, Q.; Chen, Z.; Zhang, H.; Sun, Z.; Xu, G.; Hu, G. Hypothalamus-pituitary-adrenal axis imbalance and inflammation contribute to sex differences in separation- and restraint-induced depression. Horm. Behav. 2020, 122, 104741. [CrossRef] [PubMed]

68. Oliver, D.K.; Intson, K.; Sargin, D.; Power, S.K.; McNabb, J.; Ramsey, A.J.; Lambe, E.K. Chronic social isolation exerts opposing sex-specific consequences on serotonin neuronal excitability and behaviour. Neuropharmacology 2020, 168, 108015. [CrossRef]

69. Pooley, A.E.; Benjamin, R.C.; Sreedhar, S.; Eagle, A.L.; Robison, A.J.; Mazei-Robison, M.S.; Breedlove, S.M.; Jordan, C.L. Sex differences in the traumatic stress response: The role of adult gonadal hormones. Biol. Sex Differ. 2018, 9, 1-13. [CrossRef]

70. Fester, L.; Rune, G.M. Sex neurosteroids: Hormones made by the brain for the brain. Neurosci. Lett. 2021, 753, 135849. [CrossRef]

71. Roselli, C.E.; Liu, M.; Hurn, P.D. Brain aromatization: Classic roles and new perspectives. Semin. Reprod. Med. 2009, 27, 207-217. [CrossRef]

72. Schulz, K.M.; Molenda-Figueira, H.A.; Sisk, C.L. Back to the future: The organizational-activational hypothesis adapted to puberty and adolescence. Horm. Behav. 2009, 55, 597-604. [CrossRef]

73. Crow, T.J. The XY gene hypothesis of psychosis: Origins and current status. Am. J. Med. Genet. Part B Neuropsychiatr. Genet. 2013, 162, 800-824. [CrossRef]

74. Seney, M.L.; Logan, R.W. Critical roles for developmental hormones and genetic sex in stress-induced transcriptional changes associated with depression. Neuropsychopharmacology 2021, 46, 221-222. [CrossRef]

75. Mankiw, C.; Park, M.T.M.; Reardon, P.K.; Fish, A.M.; Clasen, L.S.; Greenstein, D.; Giedd, J.N.; Blumenthal, J.D.; Lerch, J.P.; Chakravarty, M.M.; et al. Allometric analysis detects brain size-independent effects of sex and sex chromosome complement on human cerebellar organization. J. Neurosci. 2017, 37, 5221-5231. [CrossRef] [PubMed]

76. Fish, A.M.; Cachia, A.; Fischer, C.; Mankiw, C.; Reardon, P.K.; Clasen, L.S.; Blumenthal, J.D.; Greenstein, D.; Giedd, J.N.; Mangin, J.F.; et al. Influences of brain size, sex, and sex chromosome complement on the architecture of human cortical folding. Cereb. Cortex 2017, 27, 5557-5567. [CrossRef] [PubMed]

77. Nadig, A.; Reardon, P.K.; Seidlitz, J.; McDermott, C.L.; Blumenthal, J.D.; Clasen, L.S.; Lalonde, F.; Lerch, J.P.; Mallar Chakravarty, M.; Raznahan, A. Carriage of supernumerary sex chromosomes decreases the volume and alters the shape of limbic structures. eNeuro 2018, 5, 1-11. [CrossRef]

78. Cox, K.H.; Bonthuis, P.J.; Rissman, E.F. Mouse model systems to study sex chromosome genes and behavior: Relevance to humans. Front. Neuroendocrinol. 2014, 35, 405-419. [CrossRef]

79. Arnold, A.P.; Chen, X. What does the "four core genotypes" mouse model tell us about sex differences in the brain and other tissues? Front. Neuroendocrinol. 2009, 30, 1-9. [CrossRef] [PubMed]

80. Puralewski, R.; Vasilakis, G.; Seney, M.L. Sex-related factors influence expression of mood-related genes in the basolateral amygdala differentially depending on age and stress exposure. Biol. Sex Differ. 2016, 7, 1-16. [CrossRef]

81. Kopsida, E.; Lynn, P.M.; Humby, T.; Wilkinson, L.S.; Davies, W. Dissociable effects of sry and sex chromosome complement on activity, feeding and anxiety-related behaviours in mice. PLOS ONE 2013, 8, 1-15.

82. McPhie-Lalmansingh, A.A.; Tejada, L.D.; Weaver, J.L.; Rissman, E.F. Sex chromosome complement affects social interactions in mice. Horm. Behav. 2008, 54, 565-570. [CrossRef]

83. Seu, E.; Groman, S.M.; Arnold, A.P.; Jentsch, J.D. Sex chromosome complement influences operant responding for a palatable food in mice. Genes Brain Behav. 2014, 13, 527-534. [CrossRef]

84. Schuch, J.J.J.; Roest, A.M.; Nolen, W.A.; Penninx, B.W.J.H.; de Jonge, P. Gender differences in major depressive disorder: Results from the Netherlands Study of depression and anxiety. J. Affect. Disord. 2014, 156, 156-163. [CrossRef]

85. Gatewood, J.D.; Wills, A.; Shetty, S.; Xu, J.; Arnold, A.P.; Burgoyne, P.S.; Rissman, E.F. Sex chromosome complement and gonadal sex influence aggressive and parental behaviors in mice. J. Neurosci. 2006, 26, 2335-2342. [CrossRef]

86. Barker, J.M.; Torregrossa, M.M.; Arnold, A.P.; Taylor, J.R. Dissociation of genetic and hormonal influences on sex differences in alcoholism-related behaviors. J. Neurosci. 2010, 30, 9140-9144. [CrossRef] [PubMed]

87. Saunders, P.A.; Franco, T.; Sottas, C.; Maurice, T.; Ganem, G.; Veyrunes, F. Masculinised behaviour of XY females in a mammal with naturally occuring sex reversal. Sci. Rep. 2016, 6, 1-9.

88. Isles, A.R.; Davies, W.; Burrmann, D.; Burgoyne, P.S.; Wilkinson, L.S. Effects on fear reactivity in XO mice are due to haploinsufficiency of a Non-PAR X gene: Implications for emotional function in turner's syndrome. Hum. Mol. Genet. 2004, 13, $1849-1855$. [CrossRef] [PubMed]

89. McCarthy, M.M. How it's made: Organisational effects of hormones on the developing brain. J. Neuroendocrinol. 2010, 22, 736-742. [CrossRef] [PubMed]

90. McCarthy, M.M.; Wright, C.L.; Schwarz, J.M. New tricks by an old dogma: Mechanisms of the organizational/activational hypothesis of steroid-mediated sexual differentiation of brain and behavior. Horm. Behav. 2009, 55, 655-665. [CrossRef]

91. Amiel Castro, R.T.; Ehlert, U.; Fischer, S. Variation in genes and hormones of the hypothalamic-pituitary-ovarian axis in female mood disorders-A Systematic Review and Meta-analysis. Front. Neuroendocrinol. 2021, 62, 100929. [CrossRef]

92. McHenry, J.; Carrier, N.; Hull, E.; Kabbaj, M. Sex differences in anxiety and depression: Role of testosterone. Front. Neuroendocrinol. 2014, 35, 42-57. [CrossRef]

93. Seiffe, A.; Ramirez, M.F.; Barrios, C.D.; Albarrán, M.M.; Depino, A.M. Early estradiol exposure masculinizes disease-relevant behaviors in female mice. Eur. J. Neurosci. 2021, 53, 2483-2499. [CrossRef] 
94. Carrier, N.; Kabbaj, M. Testosterone and imipramine have antidepressant effects in socially isolated male but not female rats. Horm. Behav. 2012, 61, 678-685. [CrossRef]

95. Altemus, M.; Sarvaija, N.; Epperson, N. Sex differences in anxiety and depression clinical perspectives margaret. Front. Neuroendocrinol. 2014, 35, 320-330. [CrossRef]

96. Boivin, J.R.; Piekarski, D.J.; Wahlberg, J.K.; Wilbrecht, L. Age, sex, and gonadal hormones differently influence anxiety- and depression-related behavior during puberty in mice. Psychoneuroendocrinology 2017, 85, 78-87. [CrossRef]

97. Leussis, M.P.; Andersen, S.L. Is adolescence a sensitive period for depression? Behavioral and neuroanatomical findings from a social stress model. Synapse 2008, 62, 22-30. [CrossRef] [PubMed]

98. Maeng, L.Y.; Milad, M.R. Sex differences in anxiety disorders: Interactions between fear, stress, and gonadal hormones. Horm. Behav. 2015, 76, 106-117. [CrossRef] [PubMed]

99. Rubinow, D.R.; Schmidt, P.J. Is there a role for reproductive steroids in the etiology and treatment of affective disorders? Dialogues Clin. Neurosci. 2018, 20, 187-196. [PubMed]

100. Mueller, B.R.; Bale, T.L. Sex-specific programming of offspring emotionality after stress early in pregnancy. J. Neurosci. 2008, 28, 9055-9065. [CrossRef] [PubMed]

101. Davis, E.P.; Pfaff, D. Sexually dimorphic responses to early adversity: Implications for affective problems and autism spectrum disorder. Psychoneuroendocrinology 2014, 49, 11-25. [CrossRef] [PubMed]

102. Iturra-Mena, A.; Arriagada-Solimano, M.; Luttecke-Anders, A.; Dagnino-Subiabre, A. Effects of prenatal stress on anxiety- and depressive-like behaviours are sex-specific in prepubertal rats. J. Neuroendocrinol. 2018, 30, e12609. [CrossRef]

103. van den Hove, D.; Leibold, N.; Strackx, E.; Martinez-Claros, M.; Lesch, K.; Steinbusch, H.; Schruers, K.; Prickaerts, J. Prenatal stress and subsequent exposure to chronic mild stress in rats; interdependent effects on emotional behavior and the serotonergic system. Eur. Neuropsychopharmacol. 2014, 24, 595-607. [CrossRef]

104. Sickmann, H.M.; Arentzen, T.S.; Dyrby, T.B.; Plath, N.; Kristensen, M.P. Prenatal stress produces sex-specific changes in depressionlike behavior in rats: Implications for increased vulnerability in females. J. Dev. Orig. Health Dis. 2015, 6, 462-474. [CrossRef]

105. Frye, C.A.; Wawrzycki, J. Effect of prenatal stress and gonadal hormone condition on depressive behaviors of female and male rats. Horm. Behav. 2003, 44, 319-326. [CrossRef]

106. Glover, V.; Hill, J. Sex differences in the programming effects of prenatal stress on psychopathology and stress responses: An evolutionary perspective. Physiol. Behav. 2012, 106, 736-740. [CrossRef] [PubMed]

107. Schulz, K.; Pearson, J.; Neeley, E.; Berger, R.; Leonard, S.; Adams, C.; Stevens, K. Maternal Stress during pregnancy causes sex-specific alterations in offspring memory performance, social interactions, indices of anxiety, and body mass. Physiol. Behav. 2011, 104, 340-347. [CrossRef] [PubMed]

108. Sutherland, S.; Brunwasser, S.M. Sex differences in vulnerability to prenatal stress: A Review of the recent literature. Curr. Psychiatry Rep. 2018, 20, 102. [CrossRef]

109. Lei, L.; Wu, X.; Gu, H.; Ji, M.; Yang, J. Differences in DNA methylation reprogramming underlie the sexual dimorphism of behavioral disorder caused by prenatal stress in rats. Front. Neurosci. 2020, 14, 1-10. [CrossRef]

110. Sandman, C.A.; Glynn, L.M.; Davis, E.P. Is There a viability-vulnerability tradeoff? Sex differences in fetal programming. J. Psychosom. Res. 2013, 75, 327-335. [CrossRef]

111. Buss, C.; Davis, E.P.; Shahbaba, B.; Pruessner, J.C.; Head, K.; Sandman, C.A. Maternal cortisol over the course of pregnancy and subsequent child amygdala and hippocampus volumes and affective problems. Proc. Natl. Acad. Sci. USA 2012, 109, E1312-E1319. [CrossRef]

112. Juruena, M.F.; Gadelrab, R.; Cleare, A.J.; Young, A.H. Epigenetics: A missing link between early life stress and depression. Prog. Neuro-Psychopharmacol. Biol. Psychiatry 2021, 109, 110231. [CrossRef]

113. VanTieghem, M.; Tottenham, N. Neurobiological programming of early life stress: Functional development of amygdala-prefrontal circuitry and vulnerability for stress-related psychopathology. Curr. Top. Behav. Neurosci. 2018, 38, 117-136.

114. Pryce, C.R.; Feldon, J. Long-term neurobehavioural impact of the postnatal environment in rats: Manipulations, effects and mediating mechanisms. Neurosci. Biobehav. Rev. 2003, 27, 57-71. [CrossRef]

115. Grissom, E.M.; Hawley, W.R.; Bromley-Dulfano, S.S.; Marino, S.E.; Stathopoulos, N.G.; Dohanich, G.P. Learning strategy is influenced by trait anxiety and early rearing conditions in prepubertal male, but not prepubertal female rats. Neurobiol. Learn. Mem. 2012, 98, 174-181. [CrossRef] [PubMed]

116. Herzog, C.J.; Czéh, B.; Corbach, S.; Wuttke, W.; Schulte-Herbrüggen, O.; Hellweg, R.; Flügge, G.; Fuchs, E. Chronic social instability stress in female rats: A potential animal model for female depression. Neuroscience 2009, 159, 982-992. [CrossRef] [PubMed]

117. George, E.D.; Bordner, K.A.; Elwafi, H.M.; Simen, A.A. Maternal separation with early weaning: A novel mouse model of early life neglect. BMC Neurosci. 2010, 11, 1-14. [CrossRef] [PubMed]

118. Rice, C.J.; Sandman, C.A.; Lenjavi, M.R.; Baram, T.Z. A novel mouse model for acute and long-lasting consequences of early life stress. Endocrinology 2008, 149, 4892-4900. [CrossRef] [PubMed]

119. Goodwill, H.L.; Manzano-Nieves, G.; Gallo, M.; Lee, H.-I.; Oyerinde, E.; Serre, T.; Bath, K.G. Early life stress leads to sex differences in development of depressive-like outcomes in a mouse model. Neuropsychopharmacology 2019, 44,711-720. [CrossRef] [PubMed] 
120. Amiri, S.; Haj-Mirzaian, A.; Rahimi-balaei, M.; Razmi, A.; Kordjazy, N.; Shirzadian, A.; Ejtemaei Mehr, S.; Sianati, H.; Dehpour, A.R. Co-occurrence of anxiety and depressive-like behaviors following adolescent social isolation in male mice; possible role of nitrergic system. Physiol. Behav. 2015, 145, 38-44. [CrossRef]

121. Bachiller, S.; Paulus, A.; Vázquez-Reyes, S.; García-Domínguez, I.; Deierborg, T. Maternal separation leads to regional hippocampal microglial activation and alters the behavior in the adolescence in a sex-specific manner. Brain Behav. Immun. Heal. 2020, 9 , 100142. [CrossRef]

122. Cui, Y.; Cao, K.; Lin, H.; Cui, S.; Shen, C.; Wen, W.; Mo, H.; Dong, Z.; Bai, S.; Yang, L.; et al. Early-life stress induces depression-like behavior and synaptic-plasticity changes in a maternal separation rat model: Gender difference and metabolomics study. Front. Pharmacol. 2020, 11, 1-13. [CrossRef]

123. Wei, Y.; Wang, G.; Wang, H.; He, J.; Zhang, N.; Wu, Z.; Xiao, L.; Yang, C. Sex-dependent impact of different degrees of maternal separation experience on OFT behavioral performances after adult chronic unpredictable mild stress exposure in rats. Physiol. Behav. 2018, 194, 153-161. [CrossRef]

124. Huang, J.; Shen, C.; Ye, R.; Shi, Y.; Li, W. He effect of early maternal separation combined with adolescent chronic unpredictable mild stress on behavior and synaptic plasticity in adult female rats. Front. Psychiatry 2021, 5, 539299. [CrossRef]

125. Jaric, I.; Rocks, D.; Cham, H.; Herchek, A.; Kundakovic, M. Sex and estrous cycle effects on anxiety- and depression-related phenotypes in a two-hit developmental stress model. Front. Mol. Neurosci. 2019, 12, 1-15. [CrossRef] [PubMed]

126. Sun, H.; Zhang, X.; Kong, Y.; Gou, L.; Lian, B.; Wang, Y.; Jiang, L.; Li, Q.; Sun, H.; Sun, L. Maternal separation-induced histone acetylation correlates with BDNF-programmed synaptic changes in an animal model of PTSD with sex differences. Mol. Neurobiol. 2021, 58, 1738-1754. [CrossRef] [PubMed]

127. Beery, A.K.; Zucker, I. Sex bias in neuroscience and biomedical research. Neurosci. Biobehav. Rev. 2011, 35, 565-572. [CrossRef] [PubMed]

128. Will, T.R.; Proaño, S.B.; Thomas, A.M.; Kunz, L.M.; Thompson, K.C.; Ginnari, L.A.; Jones, C.H.; Lucas, S.C.; Reavis, E.M.; Dorris, D.M.; et al. Problems and progress regarding sex bias and omission in neuroscience research. eNeuro 2017, 4, 1-10. [CrossRef]

129. Mateus-Pinheiro, A.; Patrício, P.; Alves, N.D.; Machado-Santos, A.R.; Morais, M.; Bessa, J.M.; Sousa, N.; Pinto, L. The Sweet Drive Test: Refining phenotypic characterization of anhedonic behavior in rodents. Front. Behav. Neurosci. 2014, 8, 1-10. [CrossRef] [PubMed]

130. Dalla, C.; Pitychoutis, P.; Kokras, N.; Papadopoulou-Daifoti, Z. Sex differences in response to stress and expression of depressivelike behaviours in the rat. In Biological Basis of Sex Differences in Psychopharmacology. Current Topics in Behavioral Neurosciences; Neill, J.C., Kulkarni, J., Eds.; Springer: Berlin/Heidelberg, Germany, 2010; pp. 289-320.

131. Dalla, C.; Edgecomb, C.; Whetstone, A.S.; Shors, T.J. Females do not express learned helplessness like males do. Neuropsychopharmacology 2008, 33, 1559-1569. [CrossRef]

132. Kamper, E.F.; Chatzigeorgiou, A.; Tsimpoukidi, O.; Kamper, M.; Dalla, C.; Pitychoutis, P.; Papadopoulou-Daifoti, Z. Sex differences in oxidant/antioxidant balance under a chronic mild stress regime. Physiol. Behav. 2009, 98, 215-222. [CrossRef]

133. Karisetty, B.C.; Joshi, P.C.; Kumar, A.; Chakravarty, S. Sex differences in the effect of chronic mild stress on mouse prefrontal cortical BDNF levels: A role of major ovarian hormones. Neuroscience 2017, 356, 89-101. [CrossRef]

134. Konkle, A.T.M.; Baker, S.L.; Kentner, A.C.; Barbagallo, L.S.M.; Merali, Z.; Bielajew, C. Evaluation of the effects of chronic mild stressors on hedonic and physiological responses: Sex and strain compared. Brain Res. 2003, 992, 227-238. [CrossRef]

135. Xing, Y.; He, J.; Hou, J.; Lin, F.; Tian, J.; Kurihara, H. Gender differences in CMS and the effects of antidepressant venlafaxine in rats. Neurochem. Int. 2013, 63, 570-575. [CrossRef]

136. Sachs, B.; Ni, J.; Caron, M. Sex differences in response to chronic mild stress and congenital serotonin deficiency. Psychoneuroendocrinology 2014, 40, 123-129. [CrossRef] [PubMed]

137. Franceschelli, A.; Herchick, S.; Thelen, C.; Papadopoulou-Daifoti, Z.; Pitychoutis, P.M. Sex differences in the chronic mild stress model of depression. Behav. Pharmacol. 2014, 25, 372-383. [CrossRef] [PubMed]

138. Caldarone, B.J.; George, T.P.; Zachariou, V.; Picciotto, M.R. Gender differences in learned helplessness behavior are influenced by genetic background. Pharmacol. Biochem. Behav. 2000, 66, 811-817. [CrossRef]

139. Padilla, E.; Barrett, D.; Shumake, J.; Gonzalez-Lima, F. Strain, sex, and open-field behavior: Factors underlying the genetic susceptibility to helplessness. Behav. Brain Res. 2009, 201, 257-264. [CrossRef] [PubMed]

140. Jenkins, J.A.; Williams, P.; Kramer, G.L.; Davis, L.L.; Petty, F. The influence of gender and the estrous cycle on learned helplessness in the rat. Biol. Psychol. 2001, 58, 147-158. [CrossRef]

141. Setnik, B.; De Souza, F.G.; D'Almeida, V.; Nobrega, J.N. Increased homocysteine levels associated with sex and stress in the learned helplessness model of depression. Pharmacol. Biochem. Behav. 2004, 77, 155-161. [CrossRef]

142. Bland, S.T.; Schmid, M.J.; Der-Avakian, A.; Watkins, L.R.; Spencer, R.L.; Maier, S.F. Expression of C-Fos and BDNF MRNA in subregions of the prefrontal cortex of male and female rats after acute uncontrollable stress. Brain Res. 2005, 1051, 90-99. [CrossRef]

143. Haller, J.; Fuchs, E.; Halász, J.; Makara, G.B. Defeat is a major stressor in males while social instability is stressful mainly in females: Towards the development of a social stress model in female rats. Brain Res. Bull. 1999, 50, 33-39. [CrossRef]

144. Donner, N.C.; Lowry, C.A. Sex differences in anxiety and emotional behavior. Pflug. Arch. 2013, 465, 601-626. [CrossRef] 
145. Koert, A.; Ploeger, A.; Bockting, C.L.H.; Schmidt, M.V.; Lucassen, P.J.; Schrantee, A.; Mul, J.D. The social instability stress paradigm in rat and mouse: A systematic review of protocols, limitations, and recommendations. Neurobiol. Stress 2021, 15, 100410. [CrossRef]

146. Goñi-Balentziaga, O.; Perez-Tejada, J.; Renteria-Dominguez, A.; Lebeña, A.; Labaka, A. Social instability in female rodents as a model of stress related disorders: A systematic review. Physiol. Behav. 2018, 196, 190-199. [CrossRef]

147. Jarcho, M.R.; Massner, K.J.; Eggert, A.R.; Wichelt, E.L. Behavioral and physiological response to onset and termination of social instability in female mice. Horm. Behav. 2016, 78, 135-140. [CrossRef]

148. Labaka, A.; Gómez-Lázaro, E.; Vegas, O.; Pérez-Tejada, J.; Arregi, A.; Garmendia, L. Reduced hippocampal IL-10 expression, altered monoaminergic activity and anxiety and depressive-like behavior in female mice subjected to chronic social instability stress. Behav. Brain Res. 2017, 335, 8-18. [CrossRef]

149. Yohn, C.N.; Ashamalla, S.A.; Bokka, L.; Gergues, M.M.; Garino, A.; Samuels, B.A. Social instability is an effective chronic stress paradigm for both male and female mice. Neuropharmacology 2019, 160, 107780. [CrossRef] [PubMed]

150. Djordjevic, J.; Djordjevic, A.; Adzic, M.; Radojcic, M.B. Effects of chronic social isolation on wistar rat behavior and brain plasticity markers. Neuropsychobiology 2012, 66, 112-119. [CrossRef]

151. Pisu, M.G.; Garau, A.; Boero, G.; Biggio, F.; Pibiri, V.; Dore, R.; Locci, V.; Paci, E.; Porcu, P.; Serra, M. Sex differences in the outcome of juvenile social isolation on HPA axis function in rats. Neuroscience 2016, 320, 172-182. [CrossRef]

152. Hong, S.; Flashner, B.; Chiu, M.; ver Hoeve, E.; Luz, S.; Bhatnagar, S. Social isolation in adolescence alters behaviors in the forced swim and sucrose preference tests in female but not in male rats. Physiol. Behav. 2012, 105, 269-275. [CrossRef] [PubMed]

153. Weiss, I.C.; Pryce, C.R.; Jongen-Rêlo, A.L.; Nanz-Bahr, N.I.; Feldon, J. Effect of social isolation on stress-related behavioural and neuroendocrine state in the rat. Behav. Brain Res. 2004, 152, 279-295. [CrossRef] [PubMed]

154. Weintraub, A.; Singaravelu, J.; Bhatnagar, S. Enduring and sex-specific effects of adolescent social isolation in rats on adult stress reactivity. Brain Res. 2010, 1343, 83-92. [CrossRef]

155. Bale, T.L. Stress sensitivity and the development of affective disorders. Horm. Behav. 2006, 50, 529-533. [CrossRef]

156. Ennaceur, A.; Chazot, P.L. Preclinical animal anxiety research-Flaws and prejudices. Pharmacol. Res. Perspect. 2016, 4, 1-37. [CrossRef] [PubMed]

157. Sramek, J.J.; Murphy, M.F.; Cutler, N.R. Sex differences in the psychopharmacological treatment of depression. Dialogues Clin. Neurosci. 2016, 447-457.

158. Kokras, N.; Dalla, C. Preclinical sex differences in depression and antidepressant response: Implications for clinical research. J. Neurosci. Res. 2017, 95, 731-736. [CrossRef] [PubMed]

159. Williams, A.V.; Trainor, B.C. The impact of sex as a biological variable in the search for novel antidepressants. Front. Neuroendocrinol. 2018, 50, 107-117. [CrossRef] [PubMed] 